\title{
Combined main-chain/side-chain ionic liquid crystalline polymer based on 'jacketing' effect: Design, synthesis, supra-molecular self-assembly and photophysical properties
}

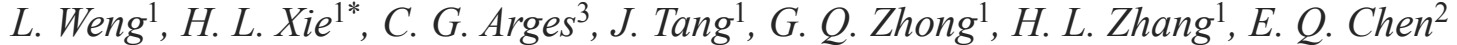 \\ ${ }^{1}$ Key Laboratory of Special Functional Polymer Materials of Hunan Province, Key Laboratory of Advanced Functional \\ Polymer Materials of Colleges and Universities of Hunan Province and Key Lab of Environment-friendly Chemistry and \\ Application in Ministry of Education, College of Chemistry, Xiangtan University, 411105 Xiangtan, Hunan Province, \\ China \\ ${ }^{2}$ Beijing National Laboratory for Molecular Sciences, College of Chemistry and Molecular Engineering, Peking \\ University, 100871 Beijing, China \\ ${ }^{3}$ Institute for Molecular Engineering, The University of Chicago, Chicago, 60637 Illinois, United States
}

\begin{abstract}
Reasonably fabricating ordered structures of ionic polymers is very important for the development of novel functional materials. By combining the ions and liquid cry stalline polymer, we successfully designed and synthesized a series of novel combined main-chain/side-chain ionic liquid crystalline polymer (MCSC-ILCPs) containing imidazolium groups and different counter-anions, poly (2,5-bis $\{[6-(4-$ butoxy-4'-imidazolium biphenyl)hexyl]oxycarbonyl $\}$ styrene salts) poly(BImBHCS-X) with the following types of counter-anions $\left(\mathrm{Br}^{-}, \mathrm{BF}_{4}^{-}, \mathrm{PF}_{6}^{-}\right.$and TFSI $\left.{ }^{-}\right)$. Combined technologies confirmed the chemical structures of the monomers and polymers with imidazolium cation and different counter-anions. Differential scanning calorimetry (DSC), polarized light microscopy (PLM) and one- and two-dimensional wide-angle X-ray diffraction (1D and 2D WAXD) results illustrated that the LC structures and the transitions of ordered structures depended on the nature of the counter-anion employed. The polymers with $\mathrm{Br}^{-}$and $\mathrm{BF}_{4}^{-}$counter-anions exhibited smectic A (SmA) LC behavior below the isotropic temperature. The another one, poly(BImBHCS-TFSI) with the large volume of the TFSI anion destroyed the packing of the LC ordered structure resulting in an amorphous structure. The photophysical properties of the polymers prepared can be adjusted by tuning the ionic interaction of the polymers by switching the counter-anion.
\end{abstract}

Keywords: polymer synthesis, molecular engineering, ionic liquid crystalline polymer, phase behavior, supermolecular structure

\section{Introduction}

Ionic liquid crystalline polymers (ILCPs) are a class of macromolecular architectures with mesogenic groups and ionic species and they have attracted great interest in the fields of polymer chemistry and materials science lately [1-3]. The combination of electrostatic interaction with liquid crystalline (LC) ordering yields ILCPs with excellent mechanical properties, rheological processability, piezoelectric performance, and optical variable performance [17]. Generally, ionic interaction promotes the ILCPs to form ionic clusters resulting in a reversible physical gelation $[1,8,9]$. Moreover, incorporation of the ions and selection of the type of ion chemistry can effectively improve the miscibility with other polymers. Therefore, ILCPs are versatile candidates to construct new high-performance functional mate-

\footnotetext{
${ }^{*}$ Corresponding author, e-mail: xhl20040731@163.com

(C) BME-PT
} 
rials and micrometer/nanometer composite materials [10-20].

In terms of the chemical structure, ILCPs can be classified as a main-chain ionic liquid crystalline polymer (MC-ILCP) or a side-chain ionic liquid crystalline polymer (SC-ILCP) $[1,3,6]$. For the MC-ILCPs, the ionic liquid crystals (ILCs) are located in the main chain of polymer. Usually, this type polymer can be synthesized by a polycondensation reaction or non-covalent bond (such as hydrogen bonding, ionic bonds etc.). Incorporation of ion groups yields significant improvement in the polymer's transverse strength, compressive strength, and miscibility of polymers or other species in MCILCPs when compared to traditional main-chain liquid crystalline polymers (MCLCPs) [21, 22]. At the same time, the implementation of the ionic groups leads to better and more diverse thermal behavior, liquid crystal behavior, and photoelectric properties [23-26]. For example, the content of sulfonic acid in ILCPs not only dictates their glass transition temperature $\left(T_{\mathrm{g}}\right)$ and melting point $\left(T_{\mathrm{m}}\right)$, but also has been demonstrated to play an important role in their supramoleculer structures [27, 28]. For MC-ILCPs with viologen, the LC properties can be controlled via tuning the main chain linkage position resulting in both thermotropic and lyotropic smectic phases [29]. For SC-ILCPs, their ILC mesogens are pendants located in the side chain or the ions are placed in the main chain and LC mesogens are situated in the side chain. Both of these ILCPs can be synthesized or assembled through free radical polymerization, silicon hydrogen addition, or non-covalent bond assembly [30-32]. Similarly to MC-ILCPs, the $T_{\mathrm{g}}$, isotropic temperature $\left(T_{\mathrm{i}}\right)$, and LC behavior of the SC-ILCPs becomes varied due to the incorporation of the different cations and anions. For instance, SC-ILCPs with sulfonic groups and carboxylic groups can self-assemble to sandwich thermotropic smectic phase structure, but a similar structure with bromide anions displays nematic phase only [33, 34].

Side chain liquid crystalline polymers (SCLCPs) without ions can be divided into two classes according to the linkage type of mesogenic groups to the polymer backbone. These two classes are: i) terminally (end-on) SCLCPs [35, 36] or ii) laterally (side-on) SCLCPs $[37,38]$. Normally, it is necessary to employ flexible spacers to decouple the interaction between the side chain and the backbone of SCLCPs $[39,40]$. However, when the flexible spacers were very short or a single carbon-carbon bond in the side-on in SCLCPs was utilized, these polymers still exhibited LC behaviors [41]. The typical example of such systems are the mesogenjacketed LC polymers (MJLCPs), [42-46] whose bulky mesogenic units are laterally attached to the polymer backbone via non- or only short spacers. The significantly high steric hindrance forces the polymer chain to become stiff. In fact, the mesogens may not be necessary as long as the bulky side groups around the backbone are large enough. For example, poly[dialkyl vinylterephthalate] (PDAVT) with an appropriate alkyl length could form a 2D hexagonal columnar LC phase $\left(\Phi_{\mathrm{H}}\right)$ [47]. Based on the PDAVT, a combined main-chain/side-chain LC polymer (MCSCLCP) poly(2,5-bis \{[6-(4-butoxy4'-oxy biphenyl) hexyl] oxy carbonyl\} styrene) (PBBHCS) have been designed and synthesized. It is found that the MCSCLCP can exhibit hierarchical supra-molecular structures with orderings on both the nanometer and subnanometer length scales [48]. Herein, we intend to incorporate ions into this kind of MCSCLCP to construct a novel combined main-chain/side-chain ionic liquid crystalline polymer (MCSC-ILCPs). The introduction of ions adds additional interactions to the existing interaction of chain biphenyl mesogens and the polymer backbone leading to more complex behavior of the system. Thus, it is hypothesized that the resulting materials could display a larger array of structural configurations when processing as a function of temperature. Ultimately, our intention is to investigate these new materials to help us to understand the supra-molecule hierarchical assembly process and structure in ILCPs. The chemical structures of the system and the corresponding model are as shown in Figure 1. It is worth mentioning that previous work has revealed that the side chains with ions and the main chain of ILCPs cannot be totally phase separated. The two entities act as a whole to form a column type structure - specifically, the hexagonal columnar LC ordered structure form [49]. In this work, the PILC prepared derives from the MCSCLCP. This system differs from previous works because not only does the spacer induce side chain and main chain phase separation, but its unique characteristics can create different LC phases due to the ionic mesogens in side chain. 


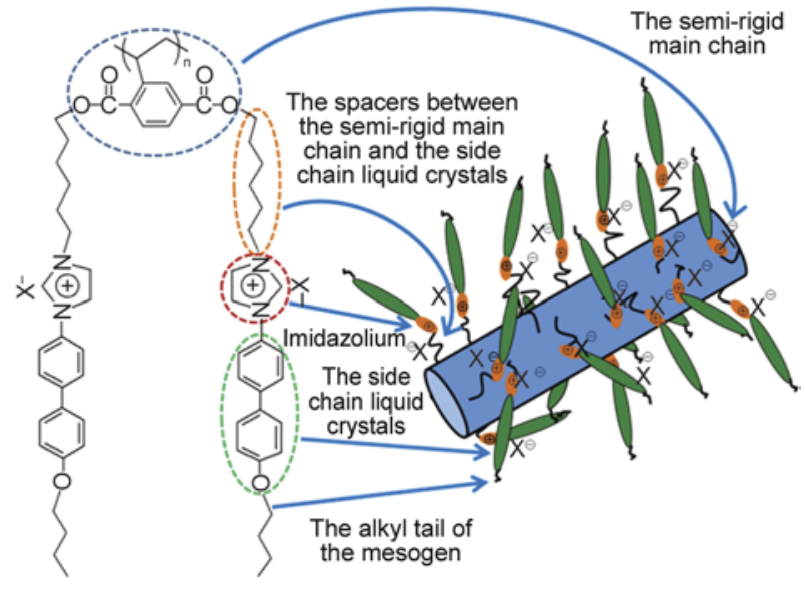

Figure 1. Chemical structures of MCSC-ILCPs poly(BImB$\mathrm{HCS}-\mathrm{X})\left(\mathrm{X}^{-}=\mathrm{Br}^{-}, \mathrm{BF}_{4}^{-}, \mathrm{PF}_{6}^{-}\right.$and TFSI $\left.{ }^{-}\right)$

Herein, we report the design and synthesis of the novel MCSC-ILCPs poly(2,5-bis \{[6-(4-butoxy-4'imidazolium biphenyl) hexyl] oxy carbonyl $\}$ styrene salts) [denoted as poly (BImBHCS-X), $\mathrm{X}^{-}=\mathrm{Br}^{-}$, $\mathrm{BF}_{4}^{-}, \mathrm{PF}_{6}^{-}$and $\mathrm{TFSI}^{-}$) via radical polymerization. Detailed characterization of the thermal stability, phase transitions and LC ordered structures of ILCPs with different counter-anions were performed. The results showed that all the samples with varying counter-anions exhibited lamellar LC phase (SmA phase) except for the sample with $\mathrm{TFSI}^{-}$. Additionally, these MCSC-ILCPs exhibited unique and enhanced fluorescence properties, which is able to promise a material for nanoscale technologies.

\section{Experimental section}

\subsection{Instruments and measurements}

Elemental analysis was carried out with an Elementar Vario EL instrument. ${ }^{1} \mathrm{H}$ NMR spectrum was taken at ambient temperature on a Bruker ARX400 spectrometer with chloroform- $d\left(\mathrm{CDCl}_{3}\right)$ as the solvent and tetramethylsilane (TMS) as the internal reference. Infrared spectroscopy was recorded on a PE Spectrum One FTIR spectrophotometer in $\mathrm{KBr}$ pellets over a range of $500-4000 \mathrm{~cm}^{-1}$.

The apparent number-average $M_{\mathrm{w}}\left(M_{\mathrm{n}}\right)$ and $M_{\mathrm{w}}$ distribution $\left(M_{\mathrm{w}} / M_{\mathrm{n}}\right)$ were measured by a gel permeation chromatography (PL-GPC120). The $\mu$-styragel columns used DMF as an eluent $(1.0 \mathrm{~mL} / \mathrm{min})$ at $35^{\circ} \mathrm{C}$. The calibration curve was obtained with linear polystyrene as standards.

Thermogravimetric analysis (TGA) was performed on a TA SDT 2960 instrument from room temperature to $600^{\circ} \mathrm{C}$ under nitrogen at a heating rate of $20^{\circ} \mathrm{C} / \mathrm{min}$. Differential scanning calorimetry (DSC) was performed on a TA DSC Q100 calorimeter under a continuous nitrogen purge and was recorded with a typical sample mass of $3 \sim 10 \mathrm{mg}$ on the standard materials (indium and zinc) at different cooling and heating rates. LC texture was examined under polarized light microscopy (PLM) (Leica DM-LM-P) coupled with a Mettler-Toledo hot stage (FP82HT). The film was casted from chloroform solution and the thickness was approximately $\sim 10 \mu \mathrm{m}$.

$1 \mathrm{D}$ wide-angle X-ray diffraction (1D WAXD) experiments were performed on a Philips $X^{\prime}$ Pert Pro diffractometer with a $3 \mathrm{~kW}$ ceramic tube as the X-ray source $(\mathrm{Cu} \mathrm{Ka})$ and an $\mathrm{X}^{\prime}$ celerator detector. The reflection peak positions were calibrated with silicon powder $\left(2 \theta>15^{\circ}\right)$ and silver behenate $\left(2 \theta<10^{\circ}\right)$. The sample stage was set horizontally and a temperature control unit (Paar Physica TCU 100) in conjunction with the diffractometer was employed to study the structure evolutions as a function of temperature. The heating and cooling rates in the WAXD experiments were $10^{\circ} \mathrm{C} / \mathrm{min}$. The 2D WAXD experiments were performed with a Bruker D8Discover in a transmission mode using a GADDS detector. The point-focused X-ray beam was aligned perpendicular to both the shear direction and the shear gradient. For both diffractometers, the X-ray sources $(\mathrm{Cu} \mathrm{KR})$ were provided by $3 \mathrm{~kW}$ ceramic tubes, and the diffraction peak positions were calibrated with silicon powder $\left(2 \theta>15^{\circ}\right)$ and silver behenate $(2 \theta<$ $10^{\circ}$ ).

UV-Vis absorption spectra were recorded with a Shimadzu MultiSpec-1501 spectrophotometer. All fluorescence measurements were carried out on a Perkin-Elmer LS55 luminescence spectrometer with excitation slit set at $5.0 \mathrm{~nm}$ and emission slit set at $3.0 \mathrm{~nm}$.

\subsection{Materials}

Tetrahydrofuran (THF), acetonitrile and N-methyl2-pyrrolidone(NMP) were desiccated by anhydrous magnesium sulfate, then filtered and purified with vacuum distillation before use. N, N-dimethylformamide (DMF) was heated circumfluence with calcium hydride for 48 hours, then filtered and obtained with vacuum distillation. Azobisisobutyronitrile (AIBN) was purified by recrystallization from ethanol before use. Lithium bis(trifluoromethanesulfonyl)imide (LiTFSI) obtained from Aladdin was 
dried under vacuum overnight. Other solvents and reagents were used as received from commercial sources.

\subsection{Synthesis}

The synthetic route of the monomers and polymers MCSC-ILCPs is given in Figure 2. The detailed synthesis and characterization of intermediates, monomers, and polymers are provided as following.

\subsection{Synthesis of MCSC-PILCs}

\subsubsection{Synthesis of 4-bromo-4'-butoxy biphenyl}

4-bromo-4'-hydroxy biphenyl $2.49 \mathrm{~g}(10 \mathrm{mmol}), 1-$ butyl bromide $2.05 \mathrm{~g}(15 \mathrm{mmol}), \mathrm{K}_{2} \mathrm{CO}_{3} 2.76 \mathrm{~g}$ $(20 \mathrm{mmol})$, and with KI $0.33 \mathrm{~g}(2 \mathrm{mmol})$ were refluxed in DMF until TLC indicated full conversion. Reaction mixture was cooled and filtered, the filter residue was washed with acetone. Filtrate was collected and removed with rotating vaporizer apparatus. The amount of DMF was reduced to $25 \%$ by vacuum distillation and the concentrated solution was precipitated in a mass of distilled water and the precipitate was filtered and collected. The product was dried in a vacuum oven over night and purified by recrystallization from ethanol, yield $82 \%$ of a white solid. ${ }^{1} \mathrm{H}$ NMR $\left(\mathrm{CDCl}_{3}\right) \delta(\mathrm{ppm})$ : 7.56-7.54 (d, 2H, Ar-H), 7.50-7.48 (d, 2H, Ar-H),
7.44-7.42 (d, 2H, Ar-H), 6.99-6.97(d, 2H, Ar-H), $4.02\left(\mathrm{t}, 2 \mathrm{H},-\mathrm{OCH}_{2}-\right), 1.81\left(\mathrm{~m}, 2 \mathrm{H},-\mathrm{CH}_{2}-\right), 1.54$ (m, 2H, $-\mathrm{CH}_{2}-$ ), 1.02-0.99 (t, 3H, $-\mathrm{CH}_{3}$ ).

\subsubsection{Synthesis of 4-butoxy-4'-imidazolyl biphenyl}

4-bromo-4'-butoxy biphenyl $3.05 \mathrm{~g}$ (10 mmol), imidazole $1.02 \mathrm{~g}(15 \mathrm{mmol}), \mathrm{K}_{2} \mathrm{CO}_{3} 2.76 \mathrm{~g}(20 \mathrm{mmol})$, and together with $\mathrm{CuI} 0.382 \mathrm{~g}(2 \mathrm{mmol})$ were put into a three-necked round bottom flask and stirred in dry N-methy-2-pyrrolidone under nitrogen atmosphere at $190^{\circ} \mathrm{C}$ for $24 \mathrm{~h}$. The mixture was cooled down, filtered and washed with dichloromethane, and then the solvent was removed with rotate vaporizing apparatus. The remainder flowed through a short column filled with neutral aluminum oxide powder, and the residual liquid was precipitated in water and filter residue was collected. The solid product was dried in a vacuum oven over night, and then purified by recrystallization from hexane, yield $40.5 \%$ of a white or silver grey solid. ${ }^{1} \mathrm{H}$ NMR $\left(\mathrm{CDCl}_{3}\right) \delta(\mathrm{ppm}): 8.03$ (s, 1H, Im-H2), 7.70-7.68 (d, $2 \mathrm{H}, \mathrm{Ar}-H), 7.56-7.54(\mathrm{~d}, 2 \mathrm{H}, \mathrm{Ar}-H), 7.48-7.46(\mathrm{~d}$, $2 \mathrm{H}, \mathrm{Ar}-H$ ), 7.37 (br s, $1 \mathrm{H}, \mathrm{Im}-H 4), 7.28$ (br s, $1 \mathrm{H}$, $\mathrm{Im}-H 5), 7.03-7.01$ (d, 2H, Ar-H), 4.04 (t, $\left.2 \mathrm{H},-\mathrm{OCH}_{2}-\right), 1.82-1.81\left(\mathrm{~m}, 2 \mathrm{H},-\mathrm{CH}_{2}-\right), 1.55(\mathrm{~m}$, $\left.2 \mathrm{H},-\mathrm{CH}_{2}-\right), 1.03-1.02\left(\mathrm{t}, 3 \mathrm{H},-\mathrm{CH}_{3}\right)$.

$\mathrm{Br}$
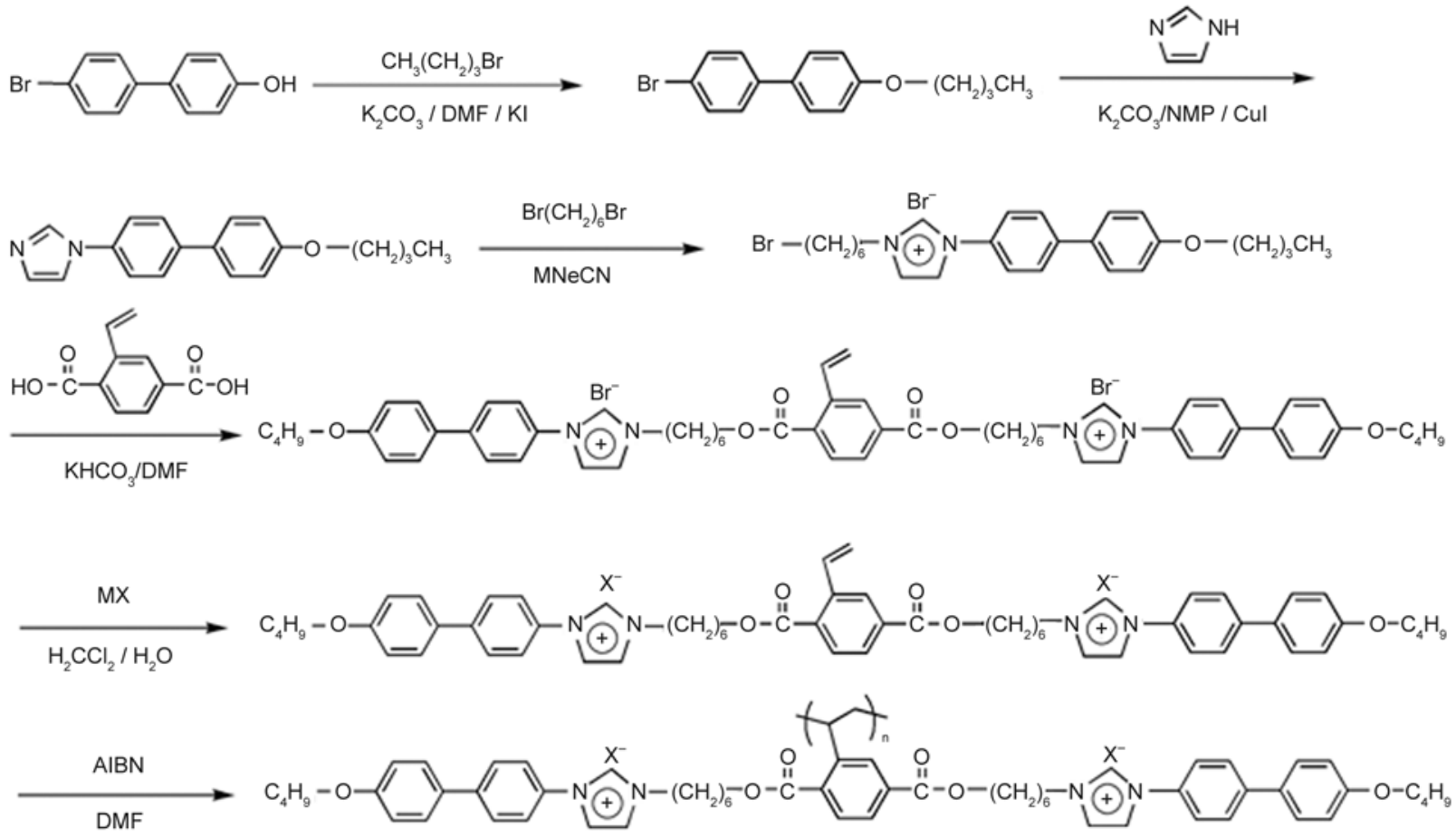

$\left(\mathrm{MX}=\mathrm{NaBF}_{4}, \mathrm{KPF}_{6}, \mathrm{LiTFSI} ; \mathrm{X}^{-}=\mathrm{Br}^{-}, \mathrm{BF}_{4}^{-}, \mathrm{PF}_{6}^{-}, \mathrm{TFSI}^{-}\right)$

Figure 2. Synthetic route of the ILCs and the corresponding MCSC-ILCPs 


\subsubsection{Synthesis of $\omega$-(4-butoxy biphenyl-4'- imidazolium)-1-bromo hexane bromide}

4-butoxy-4'-imidazolyl biphenyl $2.92 \mathrm{~g}(10 \mathrm{mmol})$,

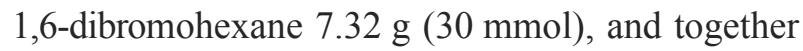
with dry acetonitrile were added into a round bottom flask and refluxed until TLC indicated full conversion. The mixture was cooled down and the solvent was removed by rotating vaporizer apparatus. The residual liquid was precipitated in ethyl acetate, and the solid was washed with THF at least three times and then dried in a vacuum oven over night. The collected product was dissolved in a little dichloromethane and purified by the silicon column using mixed solvent (dichloromethane:methanol = 10:1) as the eluent. The first ingredient was collected and the eluent was removed with rotate vaporizing apparatus, then the product dried in a vacuum oven gave a pale-grey viscous solid. Yield: $80.2 \%$. ${ }^{1} \mathrm{H} \mathrm{NMR}\left(\mathrm{CDCl}_{3}\right) \delta$ (ppm): 11.15 (s, $\left.1 \mathrm{H}, \mathrm{Im}-\mathrm{H} 2\right)$, 7.78-7.76 (d, 2H, Ar-H), 7.68-7.66 (d, 2H, Ar-H), 7.62 (br s, $1 \mathrm{H}, \mathrm{Im}-H 4), 7.50$ (br s, $1 \mathrm{H}, \mathrm{Im}-H 5)$, 7.46-7.43 (d, 2H, Ar-H), 6.94-6.92 (d, 2H, Ar-H), 4.58-4.55 (t, 2H, $\left.-\mathrm{N}^{+} \mathrm{CH}_{2}-\right)$, 3.97-3.94 (t, 2H, $\mathrm{OCH}_{2}-$ ), 3.37-3.34 (t, $\left.2 \mathrm{H},-\mathrm{CH}_{2} \mathrm{Br}\right), 2.00-1.97(\mathrm{~m}$, $\left.2 \mathrm{H},-\mathrm{CH}_{2}-\right), 1.83-1.71\left(\mathrm{~m}, 4 \mathrm{H},-\mathrm{CH}_{2}-\right), 1.49-1.41$ $\left(\mathrm{m}, 6 \mathrm{H},-\mathrm{CH}_{2}-\right), 0.96-0.92\left(\mathrm{t}, 3 \mathrm{H},-\mathrm{CH}_{3}\right)$.

\subsubsection{Synthesis of 2-vinyl p-biphthalic acid}

2-vinyl p-biphthalic acid was obtained by using the previous method from Zhang et al. [70]. ${ }^{1} \mathrm{H}$ NMR $\left(\mathrm{DMSO}-d_{6}\right) \delta(\mathrm{ppm}): 8.24(\mathrm{~s}, 1 \mathrm{H}, \mathrm{Ar}-H), 7.92(\mathrm{~d}$, $2 \mathrm{H}, \mathrm{Ar}-H), 6.67(\mathrm{~d}, 1 \mathrm{H},=\mathrm{CH}-), 5.75\left(\mathrm{~d}, 1 \mathrm{H},=\mathrm{CH}_{2}\right)$, $5.42\left(\mathrm{~d}, 1 \mathrm{H},=\mathrm{CH}_{2}\right)$.

\subsubsection{Synthesis of monomers}

2, 5-bis\{[6-(4-butoxy-4'-imidazolium-biphenyl) hexyl] oxy carbonyl? styrene bis(bromide) (BImBHCS-Br)

2-vinyl p-biphthalic acid $0.96 \mathrm{~g}(5 \mathrm{mmol})$ and potassium hydrogen carbonate $1.0 \mathrm{~g}(10 \mathrm{mmol})$ were added into a $250 \mathrm{~mL}$ round bottom flask and stirred in DMF about 30 min until the vinyl p-biphthalic acid was dissolved completely. Then the $\omega$-(4butoxy biphenyl-4'-imidazolium)-1-bromo hexane bromide $6.70 \mathrm{~g}(12.5 \mathrm{mmol})$ and nitrobenzene $0.02 \mathrm{~g}$ $(0.18 \mathrm{mmol})$ were input the flask and the mixture was stirred at $100^{\circ} \mathrm{C}$ until TLC indicated full conversion. After the reaction was over, the mixture was cooled down, filtered and the filtrate was added to ethyl acetate for precipitating. The resulting pre- cipitate was collected and washed with THF five times. The crude product was separated through a silicon column by using the ethanol solution as the eluent until the first deserted ingredient outflow completely, and then exchanging mixed solvent (dichloromethane:methanol $=5: 1$ ) as the eluent. The previous outflowing ingredient was collected. By removing the solvent with rotate vaporizing apparatus, the product dried in a freeze drying gave a paleyellow solid. Yield: $63.8 \% .{ }^{1} \mathrm{H}$ NMR $\left(\mathrm{CDCl}_{3}\right) \delta$ (ppm): 11.07 (s, 2H, Im-H2), 8.18 (s, 1H, Ar-H), 7.96-7.89 (d, 2H, Ar-H), 7.81-7.79 (d, 4H, Ar-H), 7.73 (s, 2H, Im-H4), 7.69-7.66 (d, 4H, Ar-H), 7.64 (s, 2H, Im-H5), 7.49-7.43 (d, 4H, Ar-H), 6.95 (d, $1 \mathrm{H},=\mathrm{CH}-), 6.93(\mathrm{~d}, 4 \mathrm{H}, \mathrm{Ar}-H), 5.74-5.70(\mathrm{~d}, 1 \mathrm{H}$, $=\mathrm{CH} H), 5.41-5.38(\mathrm{~d}, 1 \mathrm{H},=\mathrm{CH} H), 4.61-4.57(\mathrm{t}, 4 \mathrm{H}$, $-\mathrm{N}^{+} \mathrm{CH}_{2-}$ ) , 4.30-4.28 (t, 4H, $\left.-\mathrm{COOCH}_{2}-\right), 4.00-$ $3.96\left(\mathrm{t}, 4 \mathrm{H},-\mathrm{OCH}_{2}-\right), 2.04\left(\mathrm{~m}, 4 \mathrm{H},-\mathrm{CH}_{2}-\right), 1.79-$ $1.76\left(\mathrm{~m}, 8 \mathrm{H},-\mathrm{CH}_{2}-\right), 1.50\left(\mathrm{~m}, 12 \mathrm{H},-\mathrm{CH}_{2}-\right), 0.99-$ $0.96\left(\mathrm{t}, 6 \mathrm{H},-\mathrm{CH}_{3}\right)$.

FTIR (KBr): v O-H/Br ‥H 3441 (s), Ar C-H 3054 (w), Im C-H 2957 (s), Ar C-H 2929 (s), - $\mathrm{CH}_{2}-$ 2868 (s), -COO 1718 (s), Ar C-H 1651 (m), C=C $1608(\mathrm{~m})$, Ar skeletal vibration $1560(\mathrm{~m}), \mathrm{Im} \mathrm{C}=\mathrm{N}$ 1499 (m), $-\mathrm{CH}_{2}-1465$ (m), - $\mathrm{CH}_{3} 1384$ (m), Im C-N 1288 (m), C-O-C 1248 (s), Im skeletal vibration 1180 (w), Im C-N 1115 (m), Im C-N 1072 (m), $\mathrm{C}-\mathrm{O}-\mathrm{C} 1036$ (w), $\mathrm{Ar}-\mathrm{CH}=\mathrm{CH}_{2} 972$ (w), $\mathrm{Ar}-\mathrm{CH}=\mathrm{CH}_{2} 916$ (w), Ar C-H 824 (m), Im C-H 760 (m), Ar C-H 618 (m) cm $\mathrm{cm}^{-1}$.

Anal. Calcd for $\mathrm{C}_{60} \mathrm{H}_{7} 0 \mathrm{~N}_{4} \mathrm{O}_{6} \mathrm{Br}_{2}: \mathrm{C}, 65.43 ; \mathrm{H}$, 6.41; N, 5.09; Found: C, 64.79; H, 6.54; N, 5.08 .

\section{Anion exchange reaction for other three monomers}

Because the used anion-exchange reactions of the ILC monomers are similar, herein, we took the monomer BImBHCS- $\mathrm{BF}_{4}$ as an example to illustrate the process. The monomer BImBHCS- $\mathrm{Br}$ $3.30 \mathrm{~g}(3 \mathrm{mmol})$ was dissolved in dichloromethane and sodium fluoroborate $\left(\mathrm{NaBF}_{4}\right) 1.65 \mathrm{~g}(15 \mathrm{mmol})$ dissolved in deionized water were mixed at a $250 \mathrm{~mL}$ round bottom flask under vigorous stirring for nearly 10 hours. After the reaction complete, the mixed solution was extracted with dichloromethane $50 \mathrm{~mL}$ by twice, and washed with deionized water $50 \mathrm{~mL}$ by five times until the eluent remained clear with the addition of an aqueous solution of $\mathrm{AgNO}_{3}$. The organic phase was collected and dried with $\mathrm{MgSO}_{4}$ and filtered. The solvent was removed with rotate 
vaporizing apparatus. The product was dried in a freeze dryer.

2,5-bis \{[6-(4-butoxy-4'-imidazolium-biphenyl) hexyl] oxy carbonyl\} styrene bis(fluoroborate) (BImBHCS- $-\mathrm{BF}_{4}$ ) Yield: $89.5 \%$ of an off-white solid.

${ }^{1} \mathrm{H} \mathrm{NMR}\left(\mathrm{CDCl}_{3}\right) \delta$ (ppm): 9.25 (s, 2H, Im-H2), 8.18 (s, 1H, Ar-H), 7.99-7.93 (d, 2H, Ar-H), 7.68 (d, 4H, Ar-H), 7.63 (s, 2H, Im-H4), 7.58-7.56 (d, 4H, $\mathrm{Ar}-H), 7.47$ (s, 2H, Im-H5), 7.45-7.43 (d, 4H, $\operatorname{Ar}-H), 6.95(\mathrm{~d}, 1 \mathrm{H},=\mathrm{CH}-), 6.93(\mathrm{~d}, 4 \mathrm{H}, \mathrm{Ar}-H)$, $5.75-5.71(\mathrm{~d}, 1 \mathrm{H},=\mathrm{CH} H), 5.41-5.38(\mathrm{~d}, 1 \mathrm{H},=\mathrm{CH} H)$, 4.35-4.32 (t, 4H, $\left.-\mathrm{N}^{+} \mathrm{CH}_{2}-\right)$, 4.30-4.28 (t, 4H, $-\mathrm{COOCH}_{2}-$ ), 4.00-3.97 (t, 4H, $\left.-\mathrm{OCH}_{2}-\right), 1.98$ (m, $\left.4 \mathrm{H},-\mathrm{CH}_{2}-\right), 1.80-1.74\left(\mathrm{~m}, 8 \mathrm{H},-\mathrm{CH}_{2}-\right), 1.52-1.49$ (m, $\left.12 \mathrm{H},-\mathrm{CH}_{2}-\right), 1.01-0.98$ (t, 6H, $-\mathrm{CH}_{3}$ ).

FTIR (KBr): v O-H 3437 (s), Im C-H 3152 (w), Ar C-H 3042 (w), Im C-H 2956 (s), Ar C-H 2927 (s), $-\mathrm{CH}_{2}-2869$ (s), -COO 1718 (s), Ar C-H 1640 (w), $\mathrm{C}=\mathrm{C} 1607(\mathrm{~m})$, Ar skeletal vibration $1563(\mathrm{~m}), \mathrm{Im}$ $\mathrm{C}=\mathrm{N} 1499$ (w), $-\mathrm{CH}_{2}-1465$ (s), $-\mathrm{CH}_{3} 1382$ (m), Im C-N 1289 (m),C-O-C 1248 (s), Im skeletal vibration 1180 (m), Im C-N 1114 (m), $\mathrm{BF}_{4}^{-} 1068$ (s), $\mathrm{Ar}-\mathrm{CH}=\mathrm{CH}_{2} 972$ (w), $\mathrm{Ar}-\mathrm{CH}=\mathrm{CH}_{2} 917$ (w), Ar C-H 823(s), Im C-H 761 (m), Ar C-H 621 (m) $\mathrm{cm}^{-1}$.

Anal. Calcd for $\mathrm{C}_{60} \mathrm{H}_{70} \mathrm{~N}_{4} \mathrm{O}_{6} \mathrm{~B}_{2} \mathrm{~F}_{8}$ : C, 64.49; $\mathrm{H}$, 6.32; N, 5.02; Found: C, 64.79; H, 6.53; N, 4.82.

2,5-bis \{[6-(4-butoxy-4'-imidazolium-biphenyl) hexyl] oxy carbonyl $\}$ styrene bis(hexafluorophosphate) (BImBHCS-PF 6 ) Yield: $88.2 \%$ of a light red solid.

${ }^{1} \mathrm{H} \mathrm{NMR}\left(\mathrm{CDCl}_{3}\right) \delta$ (ppm): 8.86 (s, 2H, Im-H2), 8.18 (s, 1H, Ar-H), 7.99-7.92 (d, 2H, Ar-H), 7.61-7.59 (d, $4 \mathrm{H}, \mathrm{Ar}-H), 7.51$ (s, 2H, Im-H4), 7.48 (d, 4H, $\mathrm{Ar}-H), 7.44$ (s, 2H, Im-H5), 7.42 (d, 4H, Ar-H), 6.95 $(\mathrm{d}, 1 \mathrm{H},=\mathrm{CH}-), 6.93(\mathrm{~d}, 4 \mathrm{H}, \mathrm{Ar}-H), 5.74-5.70(\mathrm{~d}$, $1 \mathrm{H},=\mathrm{CH} H), 5.40-5.37(\mathrm{~d}, 1 \mathrm{H},=\mathrm{CH} H), 4.28(\mathrm{t}, 4 \mathrm{H}$, $\left.-\mathrm{N}^{+} \mathrm{CH}_{2}-\right), 4.28$ (t, 4H, $\left.-\mathrm{COOCH}_{2}-\right), 4.00-3.97$ (t, $\left.4 \mathrm{H},-\mathrm{OCH}_{2}-\right), 1.97\left(\mathrm{~m}, 4 \mathrm{H},-\mathrm{CH}_{2}-\right), 1.81-1.74(\mathrm{~m}$, $\left.8 \mathrm{H},-\mathrm{CH}_{2}-\right), 1.55-1.47\left(\mathrm{~m}, 12 \mathrm{H},-\mathrm{CH}_{2}-\right), 1.01-0.98$ $\left(\mathrm{t}, 6 \mathrm{H},-\mathrm{CH}_{3}\right)$.

FTIR (KBr): v O-H 3445 (s), Im C-H 3160 (w), Im C-H 2957 (m), Ar C-H 2931 (m), -CH 2870 (m), -COO 1717 (s), Ar C-H 1670(s), C=C 1607 (m), Ar skeletal vibration 1564 (w), Im $\mathrm{C}=\mathrm{N} 1499$ (s), $-\mathrm{CH}_{2}-1467$ (w), - $\mathrm{CH}_{3} 1383$ (w), Im C-N 1291 (w), C-O-C 1248 (s), Im skeletal vibration 1181 (w), Im C-N 1119 (m), Im C-N 1076 (m), $\mathrm{Ar}-\mathrm{CH}=\mathrm{CH}_{2} 972$ (w), $\mathrm{Ar}-\mathrm{CH}=\mathrm{CH}_{2} 919$ (w), $\mathrm{PF}_{6}^{-}$ 842 (vs), Im C-H 762 (w), Ar C-H 622 (m) cm ${ }^{-1}$.
Anal. Calcd for $\mathrm{C}_{60} \mathrm{H}_{70} \mathrm{~N}_{4} \mathrm{O}_{6} \mathrm{~F}_{12} \mathrm{P}_{2}$ : C, 58.42; H, 5.72; N, 4.54; Found: C, 58.78; H, 5.62; N, 4.48.

2,5-bis \{[6-(4-butoxy-4'-imidazolium-biphenyl) hexyl] oxy carbonyl $\}$ styrene bis [bis (trifluoromethanesulfonyl) imide] (BImBHCS-TFSI) Yield: $88.0 \%$ of a yellowish solid.

${ }^{1} \mathrm{H} \mathrm{NMR}\left(\mathrm{CDCl}_{3}\right) \delta(\mathrm{ppm}): 9.12$ (s, 2H, Im- $\left.\mathrm{H}_{2}\right), 8.21$ (s, 1H, Ar-H), 7.94-7.89 (d, 2H, Ar-H), 7.69-7.67 (d, 4H, Ar-H), 7.58 (s, 2H, Im-H4), 7.56-7.54 (d, $4 \mathrm{H}, \operatorname{Ar}-H), 7.50$ (s, 2H, Im-H5), $7.48(\mathrm{~d}, 4 \mathrm{H}$, $\operatorname{Ar}-H), 6.98(\mathrm{~d}, 1 \mathrm{H},=\mathrm{CH}-), 6.96(\mathrm{~d}, 4 \mathrm{H}, \mathrm{Ar}-H)$, 5.75-5.71 (d, $1 \mathrm{H},=\mathrm{CH} H), 5.40-5.38(\mathrm{~d}, 1 \mathrm{H},=\mathrm{CH} H)$, 4.33 (t, $\left.4 \mathrm{H},-\mathrm{N}^{+} \mathrm{CH}_{2}-\right)$, 4.32 (t, $4 \mathrm{H},-\mathrm{COOCH}_{2}-$ ), 4.01-3.98 (t, 4H, $\left.-\mathrm{OCH}_{2}-\right), 1.99\left(\mathrm{~m}, 4 \mathrm{H},-\mathrm{CH}_{2}-\right)$, 1.78-1.77 (m, 8H, $\left.-\mathrm{CH}_{2}-\right), 1.56-1.48(\mathrm{~m}, 12 \mathrm{H}$, $\left.-\mathrm{CH}_{2}-\right), 1.01-0.97$ (t, $\left.6 \mathrm{H},-\mathrm{CH}_{3}\right)$.

FTIR (KBr): v O-H 3450 (s), Im C-H 3139 (w), Im C-H 2954 (m), Ar C-H 2926 (s), - $\mathrm{CH}_{2}-2867$ (m), -COO 1700 (s), Ar C-H 1673(w), C=C 1605 (m), Ar skeletal vibration 1566 (w), Im C=N 1499 (m), $-\mathrm{CH}_{2}-1465$ (m), $-\mathrm{CH}_{3} 1384$ (w), TFSI ${ }^{-} 1354$ (s), Im C-N 1280 (m), C-O-C 1242 (m), TFSI ${ }^{-} 1178$ (s), Im C-N 1135 (m), TFSI 1056 (s), $\mathrm{Ar}-\mathrm{CH}=\mathrm{CH}_{2}$ 973 (w), $\mathrm{Ar}-\mathrm{CH}=\mathrm{CH}_{2} 916$ (w), $\mathrm{Ar} \mathrm{C}-\mathrm{H} 824$ (s), Im C-H 760 (w), TFSI 738 (w), Ar C-H 614 (s) cm ${ }^{-1}$. Anal. Calcd for $\mathrm{C}_{64} \mathrm{H}_{70} \mathrm{~N}_{6} \mathrm{O}_{14} \mathrm{~F}_{12} \mathrm{~S}_{4}$ : C, 51.12; H, 4.70; N, 5.59; Found: C, 51.44; H, 4.77; N, 5.56.

\subsubsection{Synthesis of MCSC-PILCs}

Poly (2, 5-bis $\{[6-(4-b u t o x y-4$ '-imidazoliumbiphenyl) hexyl] oxy carbonyl\} styrene salts) [poly $(\mathrm{BImBHCS}-\mathrm{X})]\left(\mathrm{X}^{-}=\mathrm{Br}^{-}, \mathrm{BF}_{4}^{-}, \mathrm{PF}_{6}^{-}\right.$and $\mathrm{TFSI}^{-}$). Via conventional radical polymerization, all of the MCSC-PILCs were obtained. And due to all the polymer reaction process was similar. So, a typical polymerization procedure for poly $(\mathrm{BImB}-$ $\mathrm{HCS}-\mathrm{Br}$ ) was carried out as an example. The monomer BImBHCS-Br $1.10 \mathrm{~g}(1 \mathrm{mmol}), 1 \mathrm{mg} / \mathrm{mL}$ DMF solution of AIBN $1.65 \mathrm{~mL}$ and together with the purified DMF $1.05 \mathrm{~mL}$ were input a polymerization tube. After three freeze-pump-thaw cycles, the tube was sealed off under vacuum. Polymerization was carried out at $70^{\circ} \mathrm{C}$ for $40 \mathrm{~h}$. Then the tube was opened, and the reaction mixture was diluted with a few dichloromethane, and then it was precipitated in methanol. The polymer was purified by washed with methanol three times and frozen for drying to a constant weight. The other counteranions polymers were obtained by the same way 
except the precipitator and purification reagent of poly(BImBHCS-TFSI) was diethyl ether.

\section{Results and discussion}

\subsection{Synthesis of monomers}

In this work, we have successfully designed and synthesized the targeted MCSC-ILCPs via a multistep reactions route. The monomers with different counter-anions were synthesized as shown in the Figure 2. First, we synthesized the monomer with $\mathrm{Br}^{-}$counter-anion, and then the other monomers with different counter-anions were obtained by an anion-exchange process. [50]. Figure 3 shows the ${ }^{1} \mathrm{H}$ NMR spectra of the monomers with different counter-anions. It was evident that the chemical shifts present at $6.95,5.74-5.70$, and $5.41-5.38 \mathrm{ppm}$ (denoted j, 1 and $\mathrm{m}$, respectively) represented the characteristic resonance peaks of the vinyl substituent of monomers. Completion of the anion- exchange step was determined by the changes in the assigned peaks. For example, the 2 -substituent proton hydrogen in imidazolium (denoted a) of the monomers with different counter-anions exhibited different chemical shifts depending on the type of counter-anion used. The chemical shift of the 2-substituent proton hydrogen in imidazolium were presented at $11.07,9.25,8.86$, and $9.12 \mathrm{ppm}$ for the monomers contained $\mathrm{Br}^{-}, \mathrm{BF}_{4}^{-}, \mathrm{PF}_{6}^{-}$and $\mathrm{TFSI}^{-}$, respectively. The order of the chemical shifts of the 2-substituent proton hydrogen in imidazolium monomers was monomer with $\mathrm{Br}^{-}>$monomer with $\mathrm{BF}_{4}^{-}>$monomer with $\mathrm{PF}_{6}^{-}>$monomer with $\mathrm{TFSI}^{-}$. Because large counter-anions provided better shielding, it resulted in the chemical shift being moved towards the high-field after the anion exchange step $[51,52]$.

At the same time, FTIR was utilized to confirm the NMR results and the chemical structure of the mate-
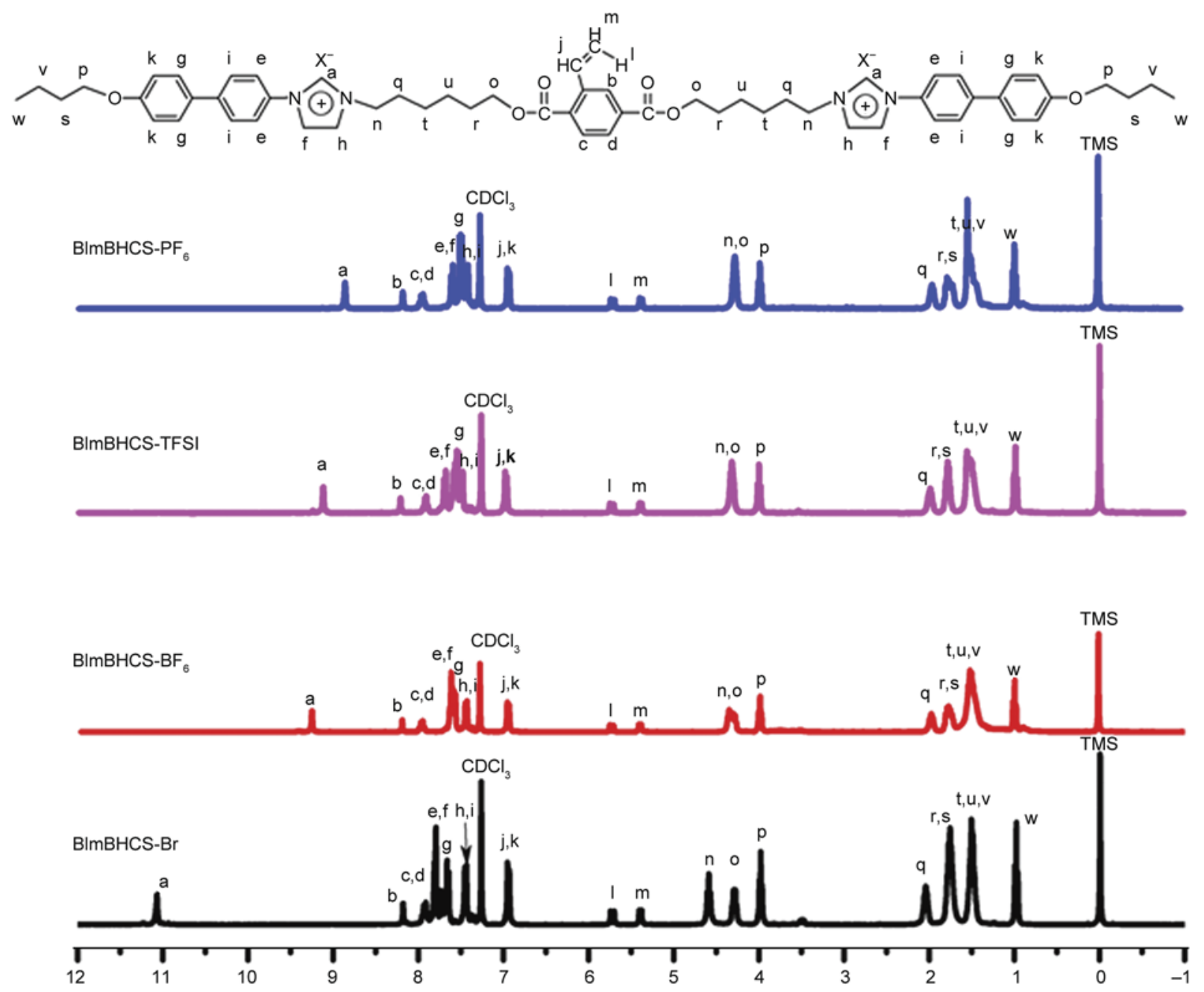

Chemical shift [ppm]

Figure 3. ${ }^{1} \mathrm{H}$ NMR spectra of ILC monomers BImBHCS-X $\left(\mathrm{X}^{-}=\mathrm{Br}^{-}, \mathrm{BF}_{4}^{-}, \mathrm{PF}_{6}^{-}\right.$and $\left.\mathrm{TFSI}^{-}\right)$ 
rials prepared. The characteristic stretching vibration peaks observed for the different counter-anions were as follows: $1068 \mathrm{~cm}^{-1}$ for $\mathrm{BF}^{-}, 842 \mathrm{~cm}^{-1}$ for $\mathrm{PF}^{-}$, and 1354, and $1178,1056,738 \mathrm{~cm}^{-1}$ for TFSI ${ }^{-}$. Because residual water was present in the sample, the stretching for $\mathrm{Br}^{-}$could not be discerned from the FTIR spectrum. Both the NMR and FTIR results were in good agreement with data found in the literatures [53, 54]. To recap, the combination of ${ }^{1} \mathrm{H}$ NMR and FTIR experiments demonstrated that the ionic liquid crystals side chain monomers with different anions were successfully prepared and the anionexchange step was successfully achieved.

\subsection{Synthesis of MCSC-ILCPs poly (BImBHCS-X) with different counter-anions}

In this study, all monomers with vinyl substituent were polymerized via a simple radical polymerization method. Herein, the polymer poly(BImBHCS$\mathrm{BF}_{4}$ ) was used as an example to describe the process. ${ }^{1} \mathrm{H}$ NMR spectra of ILC monomer BImBHCS- $-\mathrm{BF}_{4}$ and the corresponding MCSC-PILC poly(BImB-
$\mathrm{HCS}-\mathrm{BF}_{4}$ ) are depicted in Figure 4. It was observed that the characteristic chemical shifts of the vinyl substituent of BImBHCS- $-\mathrm{BF}_{4}$ were present at 6.95 , 5.75-5.71 and 5.41-5.38 ppm (denoted as $\mathrm{j}, 1$ and $\mathrm{m}$ respectively). After polymerization these characteristic resonance peaks disappeared completely. Moreover, compared to the ILC monomer BImBHCS- $-\mathrm{BF}_{4}$, the chemical shift peaks of poly $\left(\mathrm{BImBHCS}-\mathrm{BF}_{4}\right)$ became quite broad, which was consistent with the anticipated polymer structure.

To further confirm the chemical structures of the MCSC-ILCPs, we carried out the experiment of FTIR spectroscopic to analyze the materials. As mentioned above, we used the same monomer BImBHCS$\mathrm{BF}_{4}$ and the corresponding polymer poly $\left(\mathrm{BImBHCS}-\mathrm{BF}_{4}\right)$ as the example to illustrate the process. The characteristic peaks of the monomer BImBHCS- $-\mathrm{BF}_{4}$, such as $1607 \mathrm{~cm}^{-1}$, was assigned to $\mathrm{C}=\mathrm{C}$ stretching-vibration, the peaks of 972 and $916 \mathrm{~cm}^{-1}$ was assigned to $\mathrm{C}-\mathrm{H}$ out-of-plane bending vibration of the vinyl which completely disappeared after polymerization. In addition, restraint of the intra-molecular motion within the polymer material
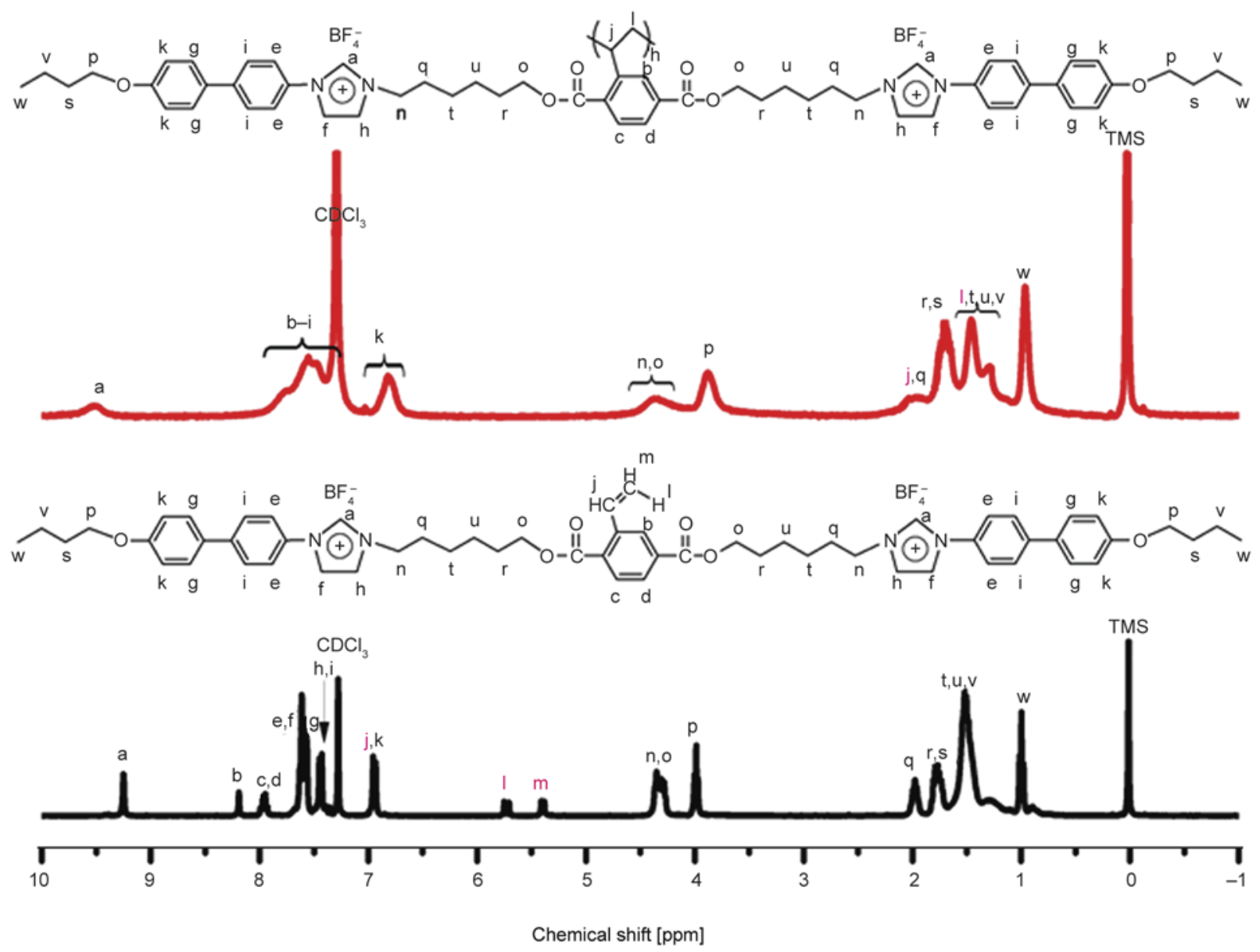

Figure 4. ${ }^{1} \mathrm{H}$ NMR spectra of $\mathrm{BImBHCS}-\mathrm{BF}_{4}$ and the corresponding poly $\left(\mathrm{BImBHCS}-\mathrm{BF}_{4}\right)$ 
Table 1. Molecular characteristics and the phase transition temperatures of poly(BImBHCS-X)

\begin{tabular}{|l|c|c|c|c|}
\hline \multicolumn{1}{|c|}{ Sample } & $\mathbf{M}_{\mathbf{n}}\left(\mathbf{\cdot 1 0}^{\mathbf{4}}\right)^{\mathbf{a}}$ & $\mathbf{M}_{\mathbf{w}} \mathbf{M}_{\mathbf{n}}{ }^{\mathbf{a}}$ & $\begin{array}{c}\mathbf{T}_{\mathbf{g}}^{\mathbf{b}} \\
{\left[{ }^{\circ} \mathbf{C}\right]}\end{array}$ & $\begin{array}{c}\mathbf{T}_{\mathbf{i}}^{\mathbf{b}} \\
{\left[{ }^{\circ} \mathbf{C}\right]}\end{array}$ \\
\hline poly(BImBHCS-Br) & 6.7 & 2.15 & 93 & - \\
\hline poly(BImBHCS-BF 4$)$ & 5.0 & 1.59 & 72 & - \\
\hline poly(BImBHCS-PF 6$)$ & 4.2 & 1.32 & 85 & 182 \\
\hline poly(BImBHCS-PTFSI) & 4.0 & 1.21 & 36 & - \\
\hline
\end{tabular}

${ }^{a}$ Determined from GPC results, linear PS as standards.

${ }^{b}$ Evaluated by DSC at a rate of $10^{\circ} \mathrm{C} / \mathrm{min}$ under cooling.

resulted in a reduction of the intensity of the infrared peaks when compared to the corresponding monomer after polymerization. The FTIR spectra were in good agreement with the results from ${ }^{1} \mathrm{H}$ NMR spectroscopy. Moreover, the molecular weight and number distribution and polydispersity of MCSC-ILCPs poly (BImBHCS-X) with different counter-anions were determined using gel permeation chromatography (GPC). The results from gel permeation chromatography are shown in Table 1.

\subsection{Thermal properties and liquid crystal ordered structures}

Before studying phase behavior and phase structure, we first investigated the thermal stability of MCSC-ILPC. Figure 5 depicts the thermal stability of the materials with different counter-anions under a nitrogen atmosphere. The results indicated that all the samples had excellent thermal stability because the samples' decomposition temperatures were above $320^{\circ} \mathrm{C}$ except that of poly(BImBHCS-Br) at about $275^{\circ} \mathrm{C}$. The thermal stability order for the series of polymers with different counter-anions was: poly (BImBHCS-TFSI), poly(BImBHCS-PF 6 ), poly $\left(\mathrm{BImBHCS}-\mathrm{BF}_{4}\right)$ and poly(BImBHCS-Br), and this ordering was consistent with the nature of the type of counter-anions in poly(BImBHCS-X) [55]. DSC was used to investigate the phase transitions of the MCSC-ILCPs. Figure 6a gives a set of DSC traces for MCSC-ILCPs that correspond to the first cooling and second heating (which were recorded at the rate of $10^{\circ} \mathrm{C} / \mathrm{min}$ ). These curves were collected after erasing the initial thermal history of the sample. Only one $T_{\mathrm{g}}$ for these MCSC-ILCPs could be observed during the whole cooling and heating process except for the sample poly(BImBHCS$\mathrm{PF}_{6}$ ), which exhibited an additional phase transition temperature. Moreover, we used the sample poly $\left(\mathrm{BImBHCS}-\mathrm{BF}_{4}\right)$ as an example to further investigate the phase transition behavior with different heat-

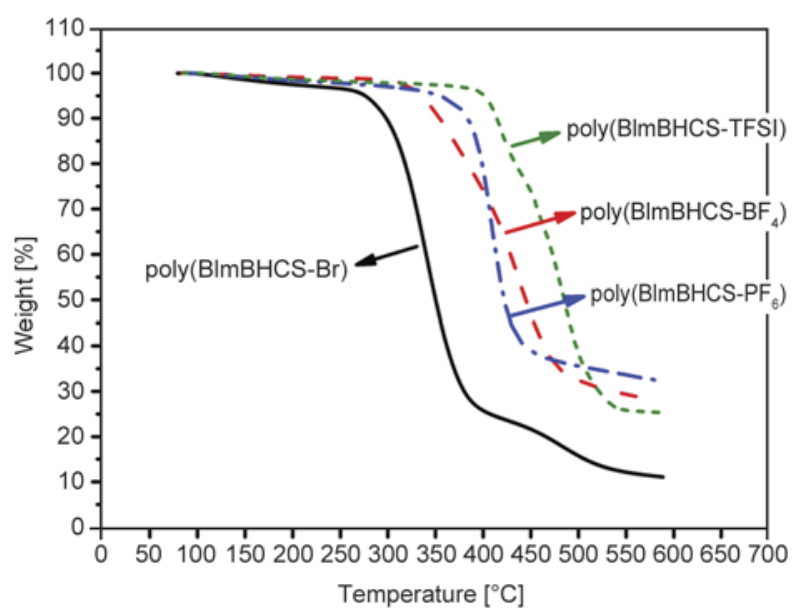

Figure 5. TGA thermograms of poly(BImBHCS-X) $\left(\mathrm{X}^{-}=\right.$ $\mathrm{Br}^{-}, \mathrm{BF}_{4}^{-}, \mathrm{PF}_{6}^{-}$and $\left.\mathrm{TFSI}^{-}\right)$at a rate of $10^{\circ} \mathrm{C} / \mathrm{min}$ in nitrogen flow

ing and cooling rates of $2.5,5,10$, and $20^{\circ} \mathrm{C} / \mathrm{min}$. However, the data in Figure $6 \mathrm{~b}$ only showed a single glass transitions $T_{\mathrm{g}}$. Based on the DSC results, the order of the $T_{\mathrm{g}}$ is poly $(\mathrm{BImBHCS}-\mathrm{Br})>$ poly $\left(\mathrm{BImBHCS}-\mathrm{PF}_{6}\right)>$ poly $\left(\mathrm{BImBHCS}-\mathrm{BF}_{4}\right)>$ poly (BImBHCS-TFSI). The observed $T_{\mathrm{g}}$ trend resulted from the different nucleophilicity and steric effect of counter-anions [56]. For example, the TFSI ${ }^{-}$ anion, which has relatively large steric hindrance and weak nucleophilicity, aided in the segmentmovement strengthening of the material [57, 58], and thus this material (poly(BImBHCS-TFSI)) gave the lowest $T_{\mathrm{g}}$ temperature among the four samples.

To study the LC properties of the class of MCSCILCPs prepared herein, we performed PLM to investigate their birefringence phenomena. First, the thin film of poly(BImBHCS-X) $\left(\mathrm{X}^{-}=\mathrm{Br}^{-}\right.$, $\mathrm{BF}_{4}^{-}, \mathrm{PF}_{6}^{-}$and $\left.\mathrm{TFSI}^{-}\right)$were drop casted from chloroform solution. As shown in Figure 7, each of the polymers exhibited strong birefringences upon heating except for poly(BImBHCS-TFSI), which indicated the existence of LC phases. Moreover, the samples MCSC-ILCPs poly(BImBHCS-Br) and poly $\left(\mathrm{BImBHCS}-\mathrm{BF}_{4}\right)$ always maintained their birefringences during heating and cooling process until decomposition. For the sample poly(BImBHCS$\mathrm{PF}_{6}$ ), the birefringences disappeared after the temperature exceeded $182^{\circ} \mathrm{C}$ during the heating process. Subsequently, the texture would reappear again during the cooling process. For sample poly(BImBHCSTFSI), no birefringences were found during the whole consecutive heating and cooling process. The appropriate volume size of the counter-anions $\mathrm{Br}^{-}$, 

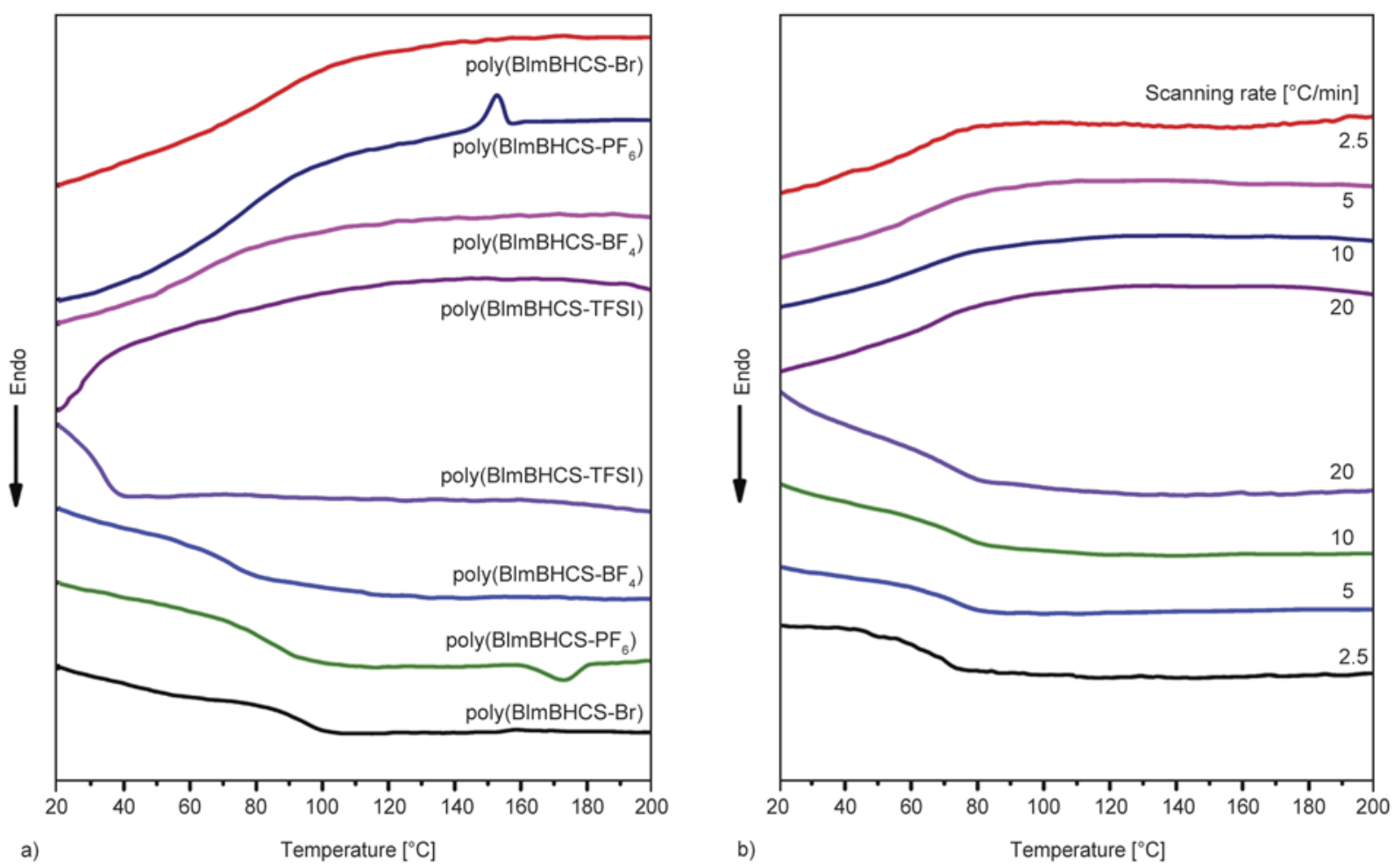

Figure 6. DSC thermograms of poly(BImBHCS-X) $\left(\mathrm{X}^{-}=\mathrm{Br}^{-}, \mathrm{BF}_{4}^{-}, \mathrm{PF}_{6}^{-}\right.$and $\left.\mathrm{TFSI}{ }^{-}\right)$at a rate of $10^{\circ} \mathrm{C} / \mathrm{min}(\mathrm{a})$ and poly $\left(\mathrm{BImBHCS}-\mathrm{BF}_{4}\right)$ at different rates $(\mathrm{b})$

$\mathrm{BF}_{4}^{-}$and $\mathrm{PF}_{6}^{-}$facilitated $\mathrm{LC}$ formation, but the $\mathrm{TFSI}^{-}$ counter-anion hindered the polymer to form the ordered structure because of its large volume. [59]. Note that the polymer PBBHCS with similar chemical structure of MCSC-ILCPs poly(BImBHCS-X) could exhibit typical different color fan texture, indicating highly ordered structure, but none of the poly(BImBHCS-X) samples exhibited any typical texture. It was obvious that the incorporation of counter-anions significantly restrained the formation of textures.

1D WAXD experiment was performed to identify the LC ordered structures of MCSC-ILCPs. Figure 8 presents the X-ray patterns of these polymers with different counter-anions. It was clearly found that all of the samples rendered an amorphous halo near $22^{\circ}$ in high-angle region. This observation was attributed to the lack of long-range order at the subnanometer length scale. On the other hand, there were other three sharp diffractions at $2 \theta$ of 1.77 , 3.56 and $5.34^{\circ}$ for poly(BImBHCS-Br) and at $2 \theta$ of $1.85,3.72$ and $5.58^{\circ}$ for poly $\left(\mathrm{BImBHCS}-\mathrm{BF}_{4}\right)$ in the low-angle region. The $q$ ratio $(q=4 \pi \cdot \sin (\theta / \lambda))$ of the diffractions were $1: 2: 3$, so these peaks were assigned to the (001), (002) and (003) plane of smectic phase (lamellar structure). Furthermore, there were two diffractions peaks at $2 \theta$ of 1.94 and $3.89^{\circ}$ for the sample poly $\left(\mathrm{BImBHCS}-\mathrm{PF}_{6}\right)$ and its $q$ ratio remained 1:2 ratio, which was attributed to (001) and (002) plane. Meanwhile, we roughly estimated the spacing of the layer was $6.00 \mathrm{~nm}$ for these MCSC-ILCPs according to the all-trans conformation, but according to 1D WAXD data it revealed that the d-spacings were $4.98,4.77$ and $4.55 \mathrm{~nm}$ for poly(BImBHCS-Br), poly(BImBHCS-BF $)$ and poly $\left(\mathrm{BImBHCS}-\mathrm{PF}_{6}\right)$, respectively. Therefore, we speculated that the SmA or SmC phases had formed. However, no sharp diffraction peak was detected in the low-angle and high-angle region for poly (BImBHCS-TFSI), only two scattering halos in the $2 \theta$ region between 2 and $35^{\circ}$ were observed, which indicated the absence of the highly ordered structures.

Variable-temperature WAXD experiments were performed to elucidate LC ordered structures of MCSC-ILCPs under different temperatures. The previous discussed WAXD results established that poly $\left(\mathrm{BImBHCS}-\mathrm{BF}_{4}\right)$ had similar LC properties and ordered structure to that of poly(BImBHCS-Br). Therefore, we used the polymer poly(BImBHCS$\mathrm{BF}_{4}$ ) as a model sample to describe the LC ordered structure transition upon temperature evolution. As 


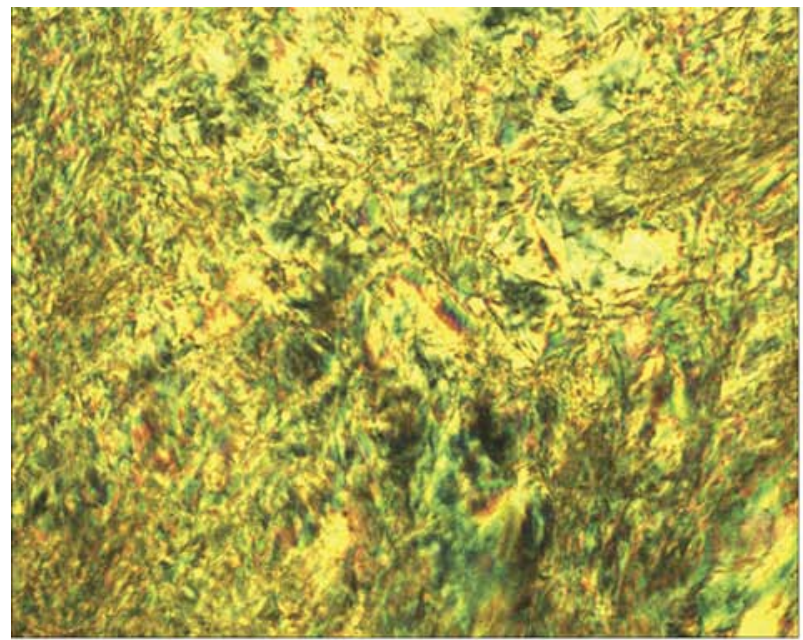

a)

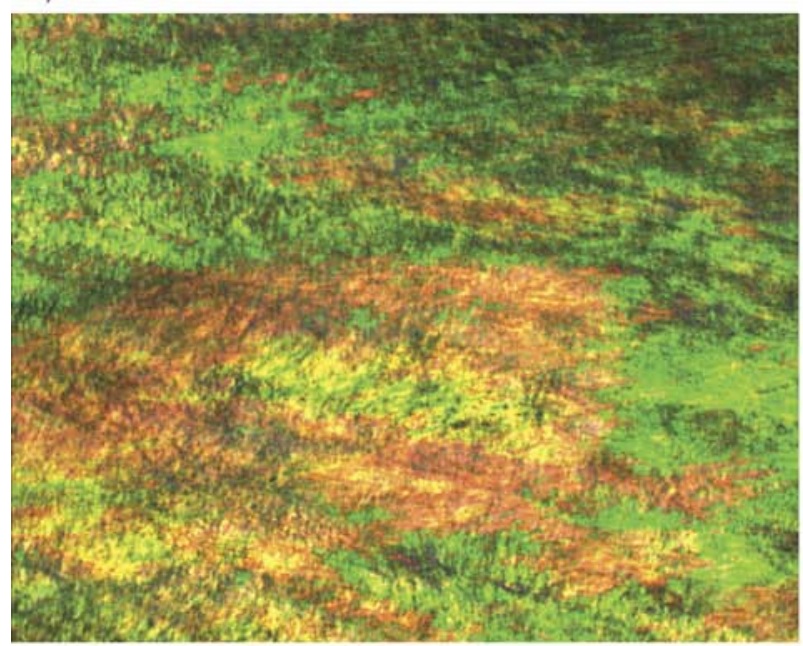

c)

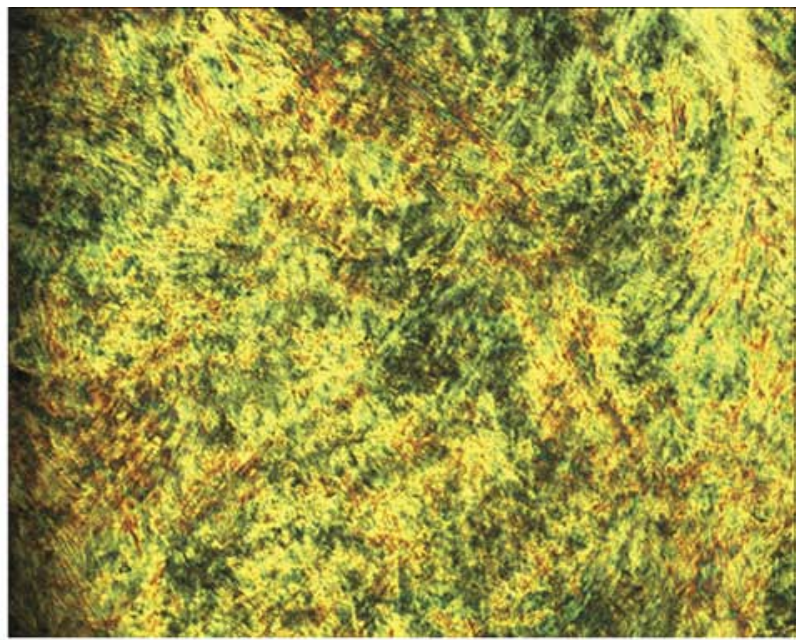

b)

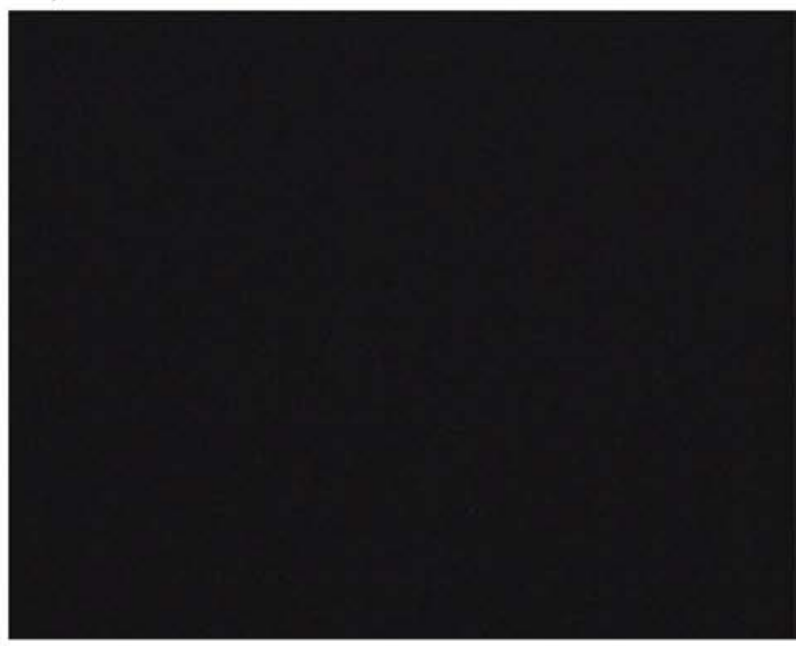

d)

Figure 7. Representative textures of poly $(\mathrm{BImBHCS}-\mathrm{Br})(\mathrm{a})$, poly $\left(\mathrm{BImBHCS}-\mathrm{BF}_{4}\right)(\mathrm{b})$, poly $\left(\mathrm{BImBHCS}-\mathrm{PF}_{6}\right)(\mathrm{c})$ and poly(BImBHCS-TFSI) (d) during heating $(200 \times$ magnification)

shown in Figure 9a, the sample of poly(BImBHCS$\mathrm{BF}_{4}$ ) rendered an amorphous halo in the high angle region and two sharp peaks at $2 \theta$ of 1.85 and $3.72^{\circ}$ assigned to (001) and (002) in the low angle region at low temperature during the heating process. With

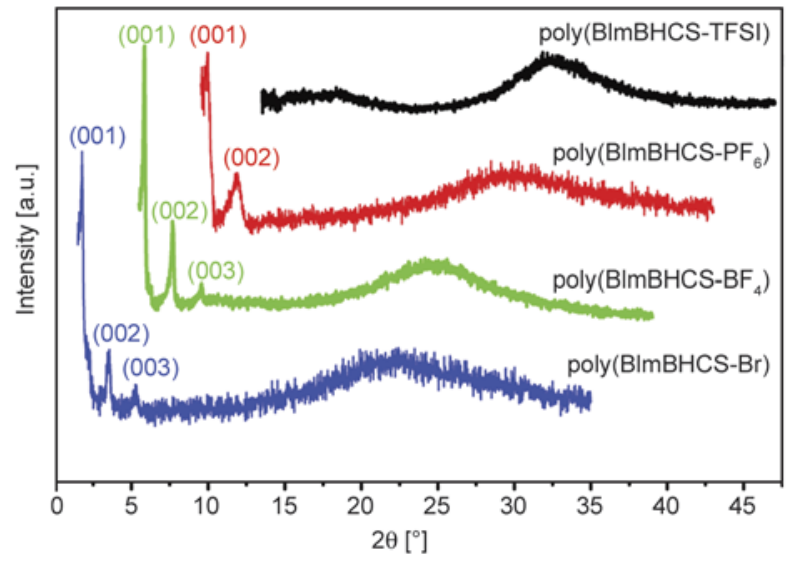

Figure 8. 1D WAXD powder patterns of poly(BImBHCS$\mathrm{X})\left(\mathrm{X}^{-}=\mathrm{Br}^{-}, \mathrm{BF}_{4}^{-}, \mathrm{PF}_{6}^{-}\right.$and $\left.\mathrm{TFSI}^{-}\right)$ the increasing of temperature, the peaks become sharper and their intensity gradually became stronger but there was relatively no shift in the peak position. At the same time, a new peak at $5.58^{\circ}$ was observed and it was assigned to (003). Furthermore, none of the diffraction peaks disappeared until heating the sample to the decomposition temperature. This observed behavior mimicked the known transitional behavior of MJLCPs. However, in the case of the sample poly(BImBHCS-PF 6 , there were some differences with the WAXD experiment results. As shown in Figure 9b, only two shape diffraction peaks of 1.94 and $3.89^{\circ}$ in the low angle region assigned to (001) and (002) remained when changing the temperature and the third diffraction peak did not always appear when increasing the temperature. When the temperature exceeded $182^{\circ} \mathrm{C}$, all of the diffraction peaks disappeared indicating the arrival of isotropic phase. During the cooling process, the 

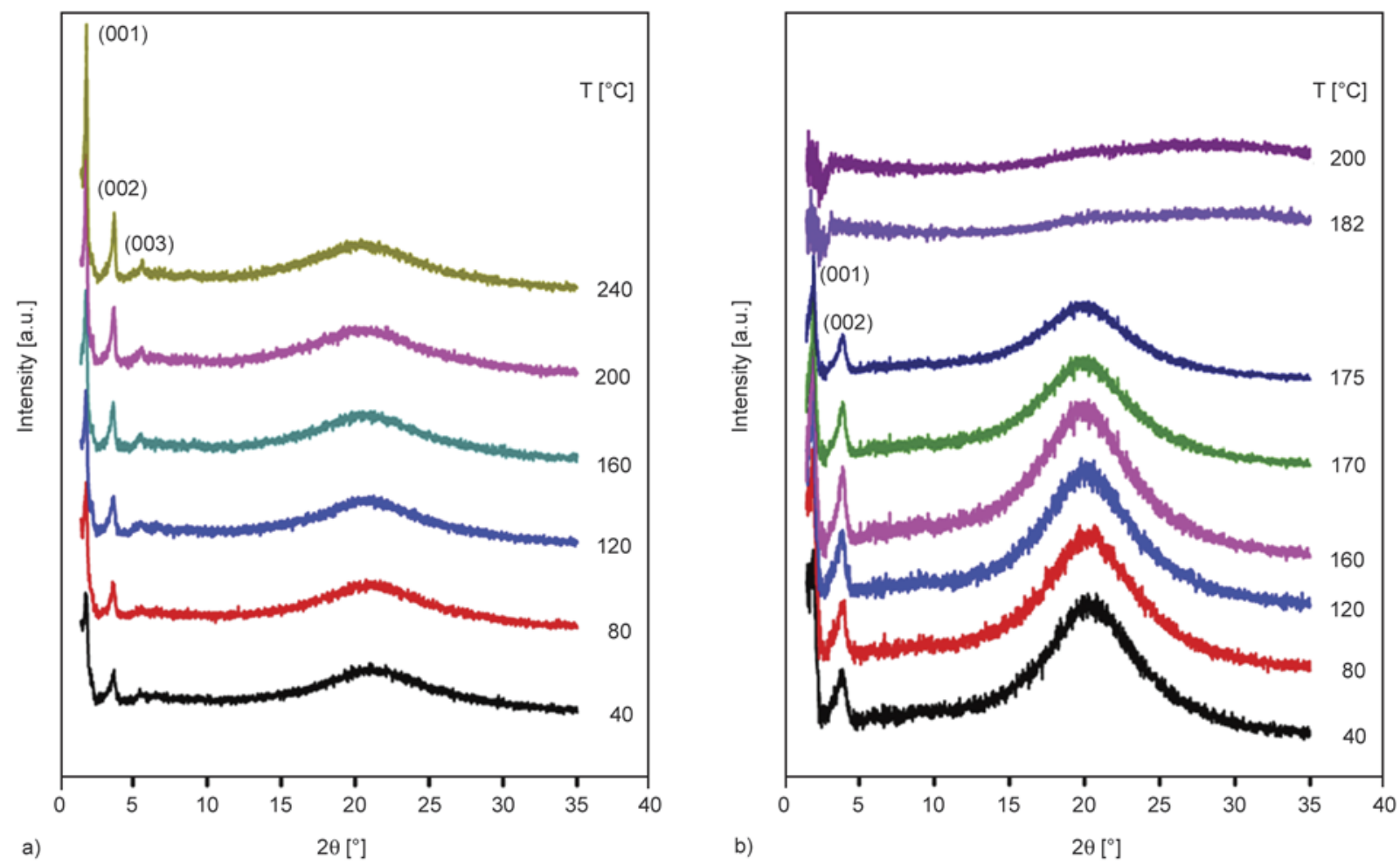

Figure 9. 1D WAXD powder patterns of poly $\left(\mathrm{BImBHCS}-\mathrm{BF}_{4}\right)(\mathrm{a})$ and poly $\left(\mathrm{BImBHCS}-\mathrm{PF}_{6}\right)(\mathrm{b})$ under heating

process was observed to be reversible because the sample poly(BImBHCS-PF 6 ) displayed lamellar diffraction peaks upon cooling. As for the sample poly(BImBHCS-TFSI), no diffraction peaks were observed during both the heating and cooling processes. The X-ray scattering results were consistent with the results of DSC and PLM.

To confirm the precise LC ordered structure of the MCSC-ILCPs poly(BImBHCS-X) $\left(\mathrm{X}^{-}=\mathrm{Br}^{-}, \mathrm{BF}_{4}^{-}\right.$ and $\left.\mathrm{PF}_{6}^{-}\right), 2 \mathrm{D}$ WAXD experiments were performed. Figure 10a schematically shows the sheared sample with the shear direction and shear gradient. The pattern for this sample poly(BImBHCS- $\left.\mathrm{PF}_{6}\right)$ is shown in Figure 10b. From the result, it was found that there are two pairs of sharp diffraction arcs at $2 \theta$ of 1.94 and $3.89^{\circ}$ assigned to (001) and (002) in the equator and the $q$ ratio remains $1: 2$, which corresponded to the $d$-spacing of 4.55 and $2.27 \mathrm{~nm}$, respectively. Meanwhile, a pair of diffuse halos displayed in the meridian region, indicated that the side-chain was laterally aligned. We can speculate the layer normal of the LC phase was perpendicular to the shear

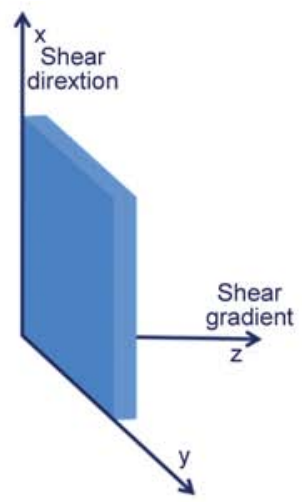

a)

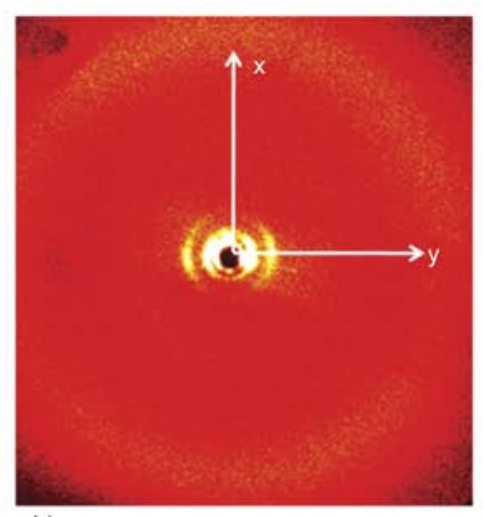

b)

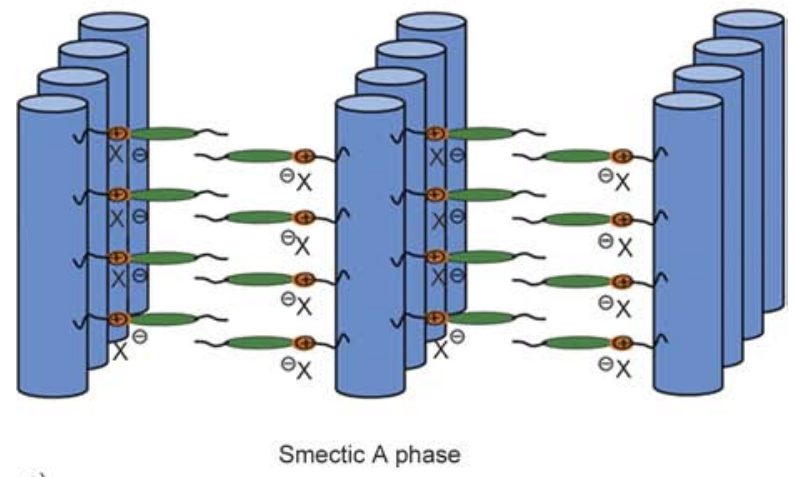

c)

Figure 10. (a) Schematic drawing of the sheared sample with the shear direction and shear gradient, respectively; (b) 2D WAXD pattern of the oriented sample poly $\left(\mathrm{BImBHCS}-\mathrm{PF}_{6}\right)$ obtained at room temperature; (c) schematic drawing of the proposed supra-molecular structures for MCSC-ILCPs poly(BImBHCS-X) with counter-anions $\mathrm{Br}^{-}$, $\mathrm{BF}_{4}^{-}, \mathrm{PF}_{6}^{-}$ 
direction. This result strongly demonstrated that the polymer formed SmA phase ordered structure, and the side chain partially overlapped between each other. Unfortunately, the other samples poly (BImBHCS-Br) and poly(BImBHCS-BF 4 ) did not display any orientation during the heating process up to decomposition. The lack of observed orientation was ascribed to the softening of the material. Based on this result, we did not obtain the 2D WAXD patterns of these two samples.

The previous MCSCLCP PBBHCS displayed a fascinating hierarchical ordered structure with both double orderings on the nanometer and subnanometer scales. The nanoscale length structure in PBBHCS was assigned to the main chain, and the subnanoscle length structure resulted from the biphenyl side group being orthogonal to the main chain [48]. However, it was not unexpected to find no high-ordered structures in the MCSC-ILCPs samples because the biphenyl mesogen were directly attached to imidazole moieties in the side groups. Usually, this attachment should be helpful for enhancing the order structure, but the results demonstrated the opposite result. This effect was ascribed to the incorporated ions, which have weakened the construction of the LC phase. When the counter-anions inserted themselves in the imidazole group, the intermolecular space increased resulting in a decreased of the molecular stacking interaction. Based on these results, we propose that high-ordered structures cannot manifest themselves in this system. Therefore, the volume of the counter-anions in these polymers demonstrated a strong influence on the stability of LC ordered structure. For example, the samples poly (BImBHCS-Br) and poly(BImBHCS-BF 4 ) with relative small volume have stable $\mathrm{LC}$ ordered structure when varying the temperature. The volume of $\mathrm{PF}_{6}^{-}$is bigger than that of $\mathrm{Br}^{-}$and $\mathrm{BF}_{4}^{-}[57,58]$ and the poly $\left(\mathrm{BImBHCS}-\mathrm{PF}_{6}\right)$ exhibited an isotropic transition temperature during the heating process. The counter-anion TFSI $^{-}$had the largest volume and not only can it weaken the intramolecular stacking of biphenyl but it was shown to destroy the scaffold of main chain LC properties. Thus, the LC ordered structures in the polymer with counter-anion $\mathrm{TFSI}^{-}$ did not always appear during the heating and cooling process in DSC scans.

Combined with the aforementioned results, it was easy to identify the three distinct classes of phase behavior in poly(BImBHCS-X) $\left(\mathrm{X}^{-}=\mathrm{Br}^{-}, \mathrm{BF}_{4}^{-}\right.$,
$\mathrm{PF}_{6}^{-}$and $\mathrm{TFSI}^{-}$) samples. The changes in phase behavior occurred by changing the counter-anion in poly(BImBHCS-X). As for MCSC-ILCPs poly (BImBHCS-X) with counter-anions $\mathrm{Br}^{-}$and $\mathrm{BF}_{4}^{-}$, the smectic phase always remained during the heating and cooling process except when they thermally decomposed. This result was consistent with the traditional MJLCPs. When the counter-anion was $\mathrm{PF}_{6}^{-}$, this kind of MCSC-PILC still maintained its smectic phase, but revealed an isotropic phase at the higher temperature. For the poly(BImBHCS-X) sample with counter-anion TFSI $^{-}$, it was determined that this sample cannot exhibit a LC phase and it only presented the isotropic status during the heating and cooling process. It is worth noting that the main chain of these MCSC-ILCPs should be columnar in spite of the incorporation of counter-anions. A number of studies have proved that MJLCPs had a rodlike columnar main chain due to the steric hindrance originating from the bulky side groups [41]. Although there was no direct evidence to indicate a columnar main chain in our MCSC-ILCPs system, the polyethylene main chain directly linked to the terephthalate unit was expected to impose a strong steric hindrance on the sample leading to a rod-like columnar structure $[48,49]$. Therefore, the main chain of these MCSC-ILCPs should be rod-like columnar because of the 'Jacketing' effect. The proposed smectic structures for this class of polymers prepared herein are depicted in Figure 10c.

\subsection{The photophysical properties of MCSC-ILCPs poly(BImBHCS-X)}

Ultraviolet-Visible (UV-Vis) and fluorescence experiments were carried out to investigate the photophysical properties of MCSC-ILCPs poly (BImBHCS-X). Figure 11 is the UV-Vis spectra of the MCSC-ILCPs poly(BImBHCS-X) $\left(\mathrm{X}^{-}=\mathrm{Br}^{-}\right.$, $\mathrm{BF}_{4}^{-}, \mathrm{PF}_{6}^{-}$and $\mathrm{TFSI}^{-}$) and MCSCLCP PBBHCS in thin films. It can be found that PBBHCS without ions incorporated into them displayed a sharp absorption maximum at $285 \mathrm{~nm}$, which was indicative of $\pi-\pi^{*}$ transitions of aromatic rings $[26,60]$. However, the samples poly(BImBHCS-X) $\left(\mathrm{X}^{-}=\mathrm{Br}^{-}, \mathrm{BF}_{4}^{-}\right.$, $\mathrm{PF}_{6}^{-}$and $\mathrm{TFSI}^{-}$) yielded a broad absorption maxima at $290 \mathrm{~nm}$, which were essentially independent of the structures of counter-anions [61, 62]. It indicates that the absorption bands of the samples originate from the same electronic transitions [63]. Compared to PBBHCS, the slight bathochromic 
shift of the characteristic absorption peak for the poly(BImBHCS-X) was found. The results come from the extended planarization of the imidazole heterocycle and biphenyl group [64, 65].

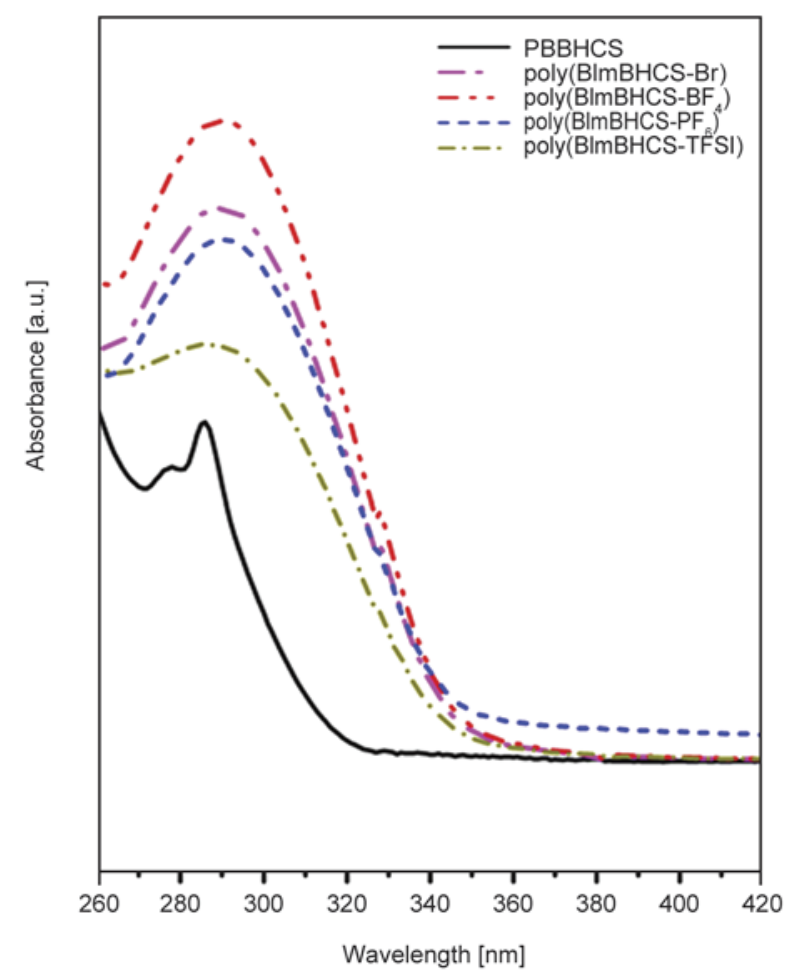

Figure 11. UV-Vis spectra of the MCSC-ILCPs poly (BImBHCS-X) in thin films. For comparison, the $\mathrm{UV}-$ Vis spectrum of PBBHCS is also included

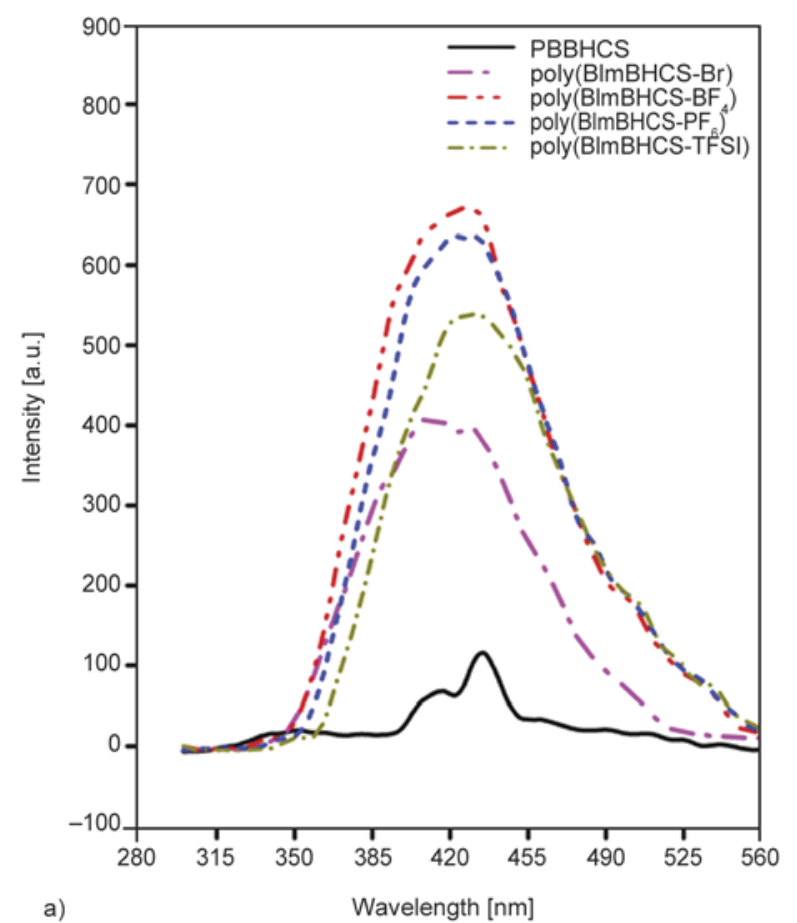

The fluorescence emission spectra of the MCSCILCPs poly(BImBHCS-X) $\left(\mathrm{X}^{-}=\mathrm{Br}^{-}, \mathrm{BF}_{4}^{-}, \mathrm{PF}_{6}^{-}\right.$ and TFSI ${ }^{-}$) and MCSCLCP PBBHCS in $\mathrm{CH}_{2} \mathrm{Cl}_{2}$ and in thin films at excitation wavelength of $290 \mathrm{~nm}$ are given in Figures 12a and 12b, respectively. In Figure $12 \mathrm{a}$, we found that the sample MCSCLCP PBBHCS only gave two weak emission peaks located at 410 and $435 \mathrm{~nm}$ in $\mathrm{CH}_{2} \mathrm{Cl}_{2}$. However, the emission spectra of MCSC-ILCPs poly(BImBHCS$\mathrm{X})\left(\mathrm{X}^{-}=\mathrm{Br}^{-}, \mathrm{BF}_{4}^{-}, \mathrm{PF}_{6}^{-}\right.$and TFSI $\left.{ }^{-}\right)$displayed some difference from that of PBBHCS. For instance, the emission peak positions for the poly(BImBHCS-X) $\left(\mathrm{X}^{-}=\mathrm{Br}^{-}, \mathrm{BF}_{4}^{-}, \mathrm{PF}_{6}^{-}\right.$and $\left.\mathrm{TFSI}^{-}\right)$samples were located at 420 and $435 \mathrm{~nm}$ indicating an obvious bathochromic shift when compared to PBBHCS. This shift originated from the extended planar conjugated system of imidazole heterocycle and biphenyl group $[64,65]$. In Figure 12b, the spectra of these samples in thin films showed some new transitions which corresponded to the obvious emission peaks at 360,420 and $485 \mathrm{~nm}$, respectively. However, for poly(BImBHCS-X), there were some interesting changes. Emission signals were observed at 393, 390, 393 and $393 \mathrm{~nm}$ for poly(BImBHCS-Br), poly $\left(\mathrm{BImBHCS}-\mathrm{BF}_{4}\right)$, poly $\left(\mathrm{BImBHCS}-\mathrm{PF}_{6}\right)$ and poly (BImBHCS-TFSI), respectively. Compared to the emission of PBBHCS, the emissions from poly (BImBHCS-X) were obviously red-shifted which

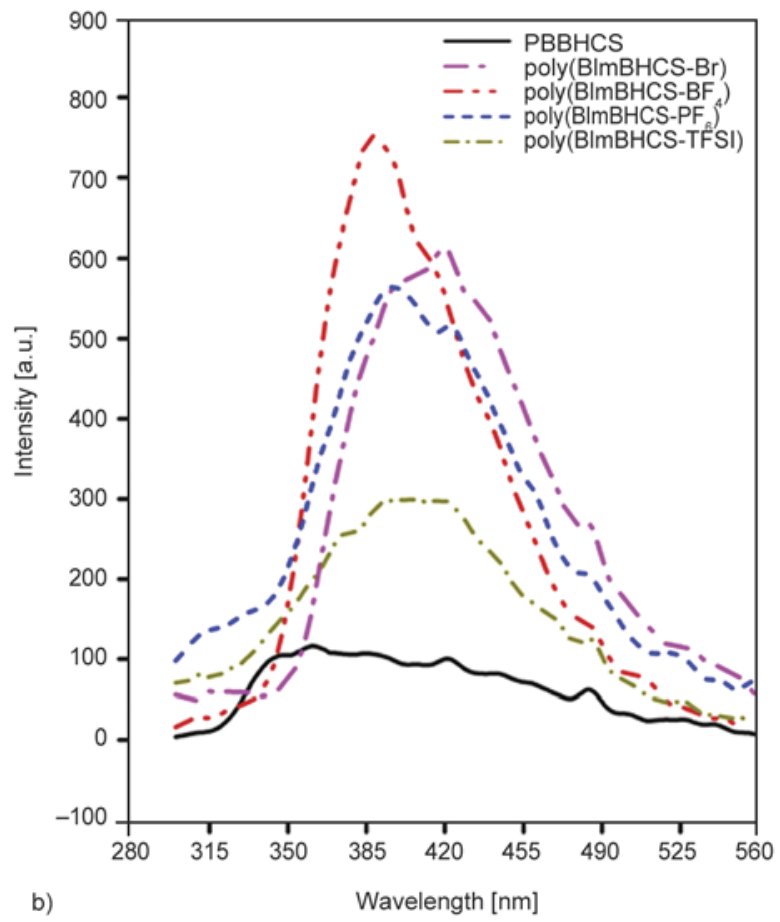

Figure 12. Emission spectra of MCSC-ILCPs poly(BImBHCS-X) $\left(\mathrm{X}^{-}=\mathrm{Br}^{-}, \mathrm{BF}_{4}^{-}, \mathrm{PF}_{6}^{-}\right.$and $\left.\mathrm{TFSI}^{-}\right)$and $\mathrm{PBBHCS}$ at excitation wavelength of $290 \mathrm{~nm}$ : (a) in $\mathrm{CH}_{2} \mathrm{Cl}_{2}$ and (b) in thin films 
derived from the electron richness of the imidazole heterocycle [64, 65]. In addition, the positions of the other two emission peaks present at 420 and $485 \mathrm{~nm}$ for poly(BImBHCS-Br), poly(BImBHCS-BF 4 ), poly $\left(\mathrm{BImBHCS}-\mathrm{PF}_{6}\right)$ and poly(BImBHCS-TFSI) changed little compared to that of PBBHCS. Meanwhile, the emission peak intensity of poly $(\mathrm{BImBHCS}-\mathrm{X})\left(\mathrm{X}^{-}=\mathrm{Br}^{-}, \mathrm{BF}_{4}^{-}, \mathrm{PF}_{6}^{-}\right.$and TFSI $\left.{ }^{-}\right)$was much stronger than that of PBBHCS. This indicated that the counter-anions inserted into the polymer samples hindered the strong high-ordering packing of the side chain biphenyl mesogens, which resulted in the absence of fluorescence quenching [66-69]. The fluorescence emission spectra results were consistent with the previous results describing the structures of the MCSC-ILCPs poly(BImBHCS-X).

\section{Conclusions}

In this article, we successfully designed and synthesized a series of novel MCSC-ILCPs poly $(\mathrm{BImBHCS}-\mathrm{X})\left(\mathrm{X}^{-}=\mathrm{Br}^{-}, \mathrm{BF}_{4}^{-}, \mathrm{PF}_{6}^{-}\right.$and $\left.\mathrm{TFSI}^{-}\right)$via radical polymerization. Each synthesized MCSCILCPs displayed phase transitions and LC properties and these material characteristics were strongly influenced by the type of counter-anion used. Due to the strong intermolecular interplay, MCSCILCPs formed lamellar ordered structures except for the poly(BImBHCS-TFSI) sample Additionally, the poly $\left(\mathrm{BImBHCS}-\mathrm{PF}_{6}\right)$ sample had isotropic phase besides the LC phase. Moreover, we found that the photophysical properties of poly(BImBHCS-X) were well-consistent with their chemical structure but practically independent on the types of counteranions they contained. The LC property of MJLCPs depended on their molecular weight [48]. Herein, all monomers of the MCSC-ILCPs poly(BImBHCS$\mathrm{X})\left(\mathrm{X}^{-}=\mathrm{Br}^{-}, \mathrm{BF}_{4}^{-}, \mathrm{PF}_{6}^{-}\right.$and $\left.\mathrm{TFSI}^{-}\right)$having vinyl substituent were polymerized to control the polymer molecule chain length utilizing the 'controlled/ living' radical polymerization method. This approach offered a new method to investigate the influence of the side chain length of the MCSC-ILCPs on the supra-molecular construction, LC behavior and photophysical properties. Continued studies with these materials (e.g., examining ion and electrical conductivity properties, optical properties, etc.) are underway and the relative results will be reported in subsequent articles.

\section{Acknowledgements}

This research is financially supported by the National Nature Science Foundation of China (21104062 and 21374092), the Doctoral Foundation of Ministry of Education of China (20114301120005), the project of Hunan Provincial Education Department (YB2013B032), Innovation Platform Open Foundation of University of Hunan Province (14K093) and Beijing National Laboratory for Molecular Sciences (BNLMS).

\section{References}

[1] Binnemans K.: Ionic liquid crystals. Chemical Reviews, 105, 4148-4204 (2005).

DOI: $10.1021 / \mathrm{cr} 0400919$

[2] Green M. D., Long T. E.: Designing imidazole-based ionic liquids and ionic liquid monomers for emerging technologies. Polymer Reviews, 49, 291-314 (2009). DOI: $10.1080 / 15583720903288914$

[3] Green O., Grubjesic S., Lee S., Firestone M. A.: The design of polymeric ionic liquids for the preparation of functional materials. Polymer Reviews, 49, 339-360 (2009).

DOI: $10.1080 / 15583720903291116$

[4] Gohy J. F., Vanhoorne P., Jérôme R.: Synthesis and preliminary characterization of model liquid crystalline ionomers. Macromolecules, 29, 3376-3383 (1996). DOI: 10.1021/ma951303u

[5] Jaeger W., Bohrisch J., Laschewsky A.: Synthetic polymers with quaternary nitrogen atoms - Synthesis and structure of the most used type of cationic polyelectrolytes. Progress in Polymer Science, 35, 511-577 (2010).

DOI: 10.1016/j.progpolymsci.2010.01.002

[6] Mecerreyes D.: Polymeric ionic liquids: Broadening the properties and applications of polyelectrolytes. Progress in Polymer Science, 36, 1629-1648 (2011).

DOI: $10.1016 /$ j.progpolymsci.2011.05.007

[7] Shi X., Shen M., Möhwald H.: Polyelectrolyte multilayer nanoreactors toward the synthesis of diverse nanostructured materials. Progress in Polymer Science, 29, 987-1019 (2004).

DOI: 10.1016/j.progpolymsci.2004.07.001

[8] Maciejewska M., Zaborski M.: Effect of ionic liquids on the dispersion of zinc oxide and silica nanoparticles, vulcanisation behaviour and properties of NBR composites. Express Polymer Letters, 8, 932-940 (2014). DOI: 10.3144 /expresspolymlett.2014.94

[9] Jazkewitsch O., Ritter H.: Polymerizable ionic liquid crystals. Macromolecular Rapid Communications, 30, 1554-1558 (2009).

DOI: $10.1002 /$ marc. 200900187

[10] Paraknowitsch J. P., Zhang J., Su D., Thomas A., Antonietti M.: Ionic liquids as precursors for nitrogen-doped graphitic carbon. Advanced Materials, 22, 87-92 (2010). DOI: $10.1002 / \mathrm{adma} .200900965$ 
[11] Yoshio M., Mukai T., Kanie K., Yoshizawa M., Ohno H., Kato T.: Layered ionic liquids: Anisotropic ion conduction in new self-organized liquid-crystalline materials. Advanced Materials, 14, 351-354 (2002).

DOI: 10.1002/1521-4095(20020304)14:5<351::AIDADMA351>3.0.CO;2-D

[12] Kato T.: From nanostructured liquid crystals to polymer-based electrolytes. Angewandte Chemie International Edition, 49, 7847-7848 (2010). DOI: $10.1002 /$ anie. 201000707

[13] Li W., Zhang J., Li B., Zhang M., Wu L.: Branched quaternary ammoniumamphiphiles: Nematic ionic liquid crystals near room temperature. Chemical Communications, 2009, 5269-5271 (2009).

DOI: 10.1039/B909605A

[14] Mao Y., Zhang X-A., Xu H-P., Yuan W-Z., Zhao H., Qin A-J., Sun J-Z., Tang B. Z.: Synthesis of polyelectrolytic polyacetylene derivatives by quaternization of poly(pyridylacetylene). Chinese Journal of Polymer Science, 29, 133-140 (2011).

DOI: $10.1007 / \mathrm{s} 10118-011-1032-\mathrm{Z}$

[15] Wen Y-P., Li D., Lu Y., He H-H., Xu J-K., Duan X-M., Liu M.: Poly(3,4-ethylenedioxythiophene methanol)/ ascorbate oxidase/nafion-single-walled carbon nanotubes biosensor for voltammetric detection of vitamin C. Chinese Journal of Polymer Science, 30, 460-469 (2012). DOI: $10.1007 / \mathrm{s} 10118-012-1140-4$

[16] Zhang H-Y., Li X-Y., Wang X-G.: Nanomechanical properties of polyaniline and azo polyelectrolyte multilayer films. Chinese Journal of Polymer Science, 28, 269-275 (2010).

DOI: $10.1007 / \mathrm{s} 10118-010-9066-1$

[17] Shimura H., Yoshio M., Hoshino K., Mukai T., Ohno H., Kato T.: Noncovalent approach to one-dimensional ion conductors: Enhancement of ionic conductivities in nanostructured columnar liquid crystals. Journal of the American Chemical Society, 130, 1759-1765 (2008). DOI: $10.1021 / \mathrm{ja} 0775220$

[18] Percec V., Johansson G., Ungar G., Zhou J.: Fluorophobic effect induces the self-assembly of semifluorinated tapered monodendrons containing crown ethers into supramolecular columnar dendrimers which exhibit a homeotropic hexagonal columnar liquid crystalline phase. Journal of the American Chemical Society, 118, 9855-9866 (1996).

DOI: $10.1021 /$ ja9615738

[19] Liu F., Wang L., Sun Q., Zhu L., Meng X., Xiao F-S.: Transesterification catalyzed by ionic liquids on superhydrophobic mesoporous polymers: Heterogeneous catalysts that are faster than homogeneous catalysts. Journal of the American Chemical Society, 134, 1694816950 (2012).

DOI: $10.1021 / \mathrm{ja} 307455 \mathrm{w}$
[20] Ichikawa T., Yoshio M., Hamasaki A., Mukai T., Ohno H., Kato T.: Self-organization of room-temperature ionic liquids exhibiting liquid-crystalline bicontinuous cubic phases: Formation of nano-ion channel networks. Journal of the American Chemical Society, 129, $10662-$ 10663 (2007).

DOI: $10.1021 / \mathrm{ja} 0740418$

[21] Xue Y., Hara M., Yoon H.: Ionic naphthalene thermotropic copolyesters: Enhanced compressive properties of fibers. Macromolecules, 34, 844-851 (2001). DOI: $\underline{10.1021 / \mathrm{ma} 000984 \mathrm{c}}$

[22] Xue Y., Hara M.: Ionic naphthalene thermotropic copolyesters: Effect of ionic content. Macromolecules, 30, 3803-3812 (1997). DOI: $10.1021 / \mathrm{ma961703x}$

[23] Zhang A., Zhang B., Feng Z.: Compatibilization by main-chain thermotropic liquid crystalline ionomer of blends of PBT/PP. Journal of Applied Polymer Science, 85, 1110-1117 (2002).

DOI: $10.1002 / a p p .10629$

[24] González-Bellavista A., Macanás J., Muñoz M., Fabregas E.: Sulfonated poly(ether ether ketone), an ion conducting polymer, as alternative polymeric membrane for the construction of anion-selective electrodes. Sensors and Actuators B: Chemical, 125, 100105 (2007).

DOI: $10.1016 /$ j.snb.2007.01.051

[25] Bhowmik P. K., Akhter S., Han H.: Thermotropic liquid crystalline main-chain viologen polymers. Journal of Polymer Science Part A: Polymer Chemistry, 33, 19271933 (1995). DOI: $10.1002 /$ pola.1995.080331123

[26] Bhowmik P. K., Molla A. H., Han H., Gangoda M. E., Bose R. N.: Lyotropic liquid crystalline main-chain viologen polymers: Homopolymer of 4,4'-bipyridyl with the ditosylate of trans-1,4-cyclohexanedimethanol and its copolymers with the ditosylate of 1,8-octanediol. Macromolecules, 31, 621-630 (1998).

DOI: $10.1021 / \mathrm{ma971115z}$

[27] Bockstaller M., Köhler W., Wegner G., Vlassopoulos D., Fytas G.: Hierarchical structures of a synthetic rodlike polyelectrolyte in water. Macromolecules, 33, 39513953 (2000).

DOI: $10.1021 / \mathrm{ma} 000190 \mathrm{y}$

[28] Bockstaller M., Köhler W., Wegner G., Vlassopoulos D., Fytas G.: Levels of structure formation in aqueous solutions of anisotropic association colloids consisting of rodlike polyelectrolytes. Macromolecules, 34, 63596366 (2001).

DOI: $10.1021 / \mathrm{ma} 010027 \mathrm{i}$

[29] Bhowmik P. K., Han H., Cebe J. J., Burchett R. A., Sarker A. M.: Main-chain viologen polymers with organic counterions exhibiting thermotropic liquidcrystalline and fluorescent properties. Journal of Polymer Science Part A: Polymer Chemistry, 40, 659-674 (2002).

DOI: $10.1002 /$ pola.10134 
[30] Roche P., ZhaoY.: Side-chain liquid crystalline ionomers. 2. Orientation in a magnetic field. Macromolecules, 28, 2819-2824 (1995).

DOI: $10.1021 / \mathrm{ma} 00112 \mathrm{a} 029$

[31] Ruokolainen J., Mäkinen R., Torkkeli M., Mäkelä T., Serimaa R., ten Brinke G., Ikkala O.: Switching supramolecular polymeric materials with multiple length scales. Science, 280, 557-560 (1998).

DOI: $10.1126 /$ science.280.5363.557

[32] Zhang B-Y., Sun Q-J., Tian M., Ren S-C.: Synthesis and mesomorphic properties of side-chain liquid crystalline ionomers containing sulfonic acid groups. Journal of Applied Polymer Science, 104, 304-309 (2007). DOI: 10.1002 /app.25730

[33] Ujiie S., Iimura K.: Thermal properties and ferroelectric like behavior of liquid-crystalline ionic polyethylenimine derivative. Chemistry Letters, 20, 1969-1972 (1991).

DOI: $10.1246 / \mathrm{cl} .1991 .1969$

[34] Chovino C., Frere Y., Guillon D., Gramain P.: Effect of smectogenicity of the ionic groups on the thermotropic liquid crystalline behavior of pyridinium and poly(4vinylpyridinium) salts quaternized with mesogenic groups. Journal of Polymer Science Part A: Polymer Chemistry, 35, 2569-2577 (1997).

DOI: 10.1002/(SICI)1099-0518(19970930)35:13<2569 $\because$ AID-POLA4>3.0.CO;2-M

[35] Bazuin C. G., Brandys F. A.: Novel liquid-crystalline polymeric materials via noncovalent 'grafting'. Chemistry of Materials, 4, 970-972 (1992).

DOI: $10.1021 / \mathrm{cm} 00023 \mathrm{a} 005$

[36] KatoT., Kihara H., Ujiie S., Uryu T., Fréchet J. M. J.: Structures and properties of supramolecular liquidcrystalline side-chain polymers built through intermolecular hydrogen bonds. Macromolecules, 29, 87348739 (1996). DOI: $10.1021 / \mathrm{ma9609341}$

[37] Qi B., Lu S. R., Xiao X. E., Pan L. L., Tan F. Z., Yu, J. H.: Enhanced thermal and mechanical properties of epoxy composites by mixing thermotropic liquid crystalline epoxy grafted graphene oxide. Express Polymer Letters, 8, 467-479 (2014).

DOI: $10.3144 /$ expresspolymlett.2014.51

[38] Percec V., Hahn B.: Liquid crystalline polymers containing heterocycloalkanediyl groups as mesogens. 7. Molecular weight and composition effects on the phase transitions of poly(methylsiloxane)s and poly (methylsiloxane-co-dimethylsiloxane)s containing 2-[4-(2(S)methyl-1-butoxy)phenyl]-5-(11-undecanyl)-1,3,2-dioxaborinane side groups. Macromolecules, 22, 1588-1599 (1989). DOI: $10.1021 / \mathrm{ma} 00194 \mathrm{a} 014$

[39] Finkelmann H., Ringsdorf H., Wendorff J. H.: Model considerations and examples of enantiotropic liquid crystalline polymers. Polyreactions in ordered systems. Die Makromolekulare Chemie, 179, 273-276 (1978). DOI: $10.1002 /$ macp.1978.021790129
[40] Finkelmann H., Happ M., Portugal M., Ringsdorf H.: Liquid crystalline polymers with biphenyl-moieties as mesogenic group. Die Makromolekulare Chemie, 179, 2541-2544 (1978).

DOI: 10.1002/macp.1978.021791018

[41] Chen X-F., Shen Z., Wan X-H., Fan X-H., Chen E-Q., Ma Y., Zhou Q-F.: Mesogen-jacketed liquid crystalline polymers. Chemical Society Reviews, 39, 3072-3101 (2010). DOI: $10.1039 / \mathrm{B} 814540 \mathrm{G}$

[42] Zhou Q. F., Li H. M., Feng X. D.: Synthesis of liquidcrystalline polyacrylates with laterally substituted mesogens. Macromolecules, 20, 233-234 (1987). DOI: $10.1021 / \mathrm{ma} 00167 \mathrm{a} 042$

[43] Zhou Q., Li Z., Zhang Z., Pei X.: Studies on the postpolymerization of a liquid-crystal polymer with Xshaped mesogens. Macromolecules, 22, 3821-3823 (1989). DOI: $10.1021 / \mathrm{ma} 00199 \mathrm{a} 062$

[44] Yang Q., Xu Y., Jin H., Shen Z., Chen X., Zou D., Fan X., Zhou Q.: A novel mesogen-jacketed liquid crystalline electroluminescent polymer with both thiophene and oxadiazole in conjugated side chain. Journal of Polymer Science Part A: Polymer Chemistry, 48, 15021515 (2010). DOI: $10.1002 /$ pola.23908

[45] Wen G-H., Zhang B., Xie H-L., Liu X., Zhong G-Q., Zhang H-L., Chen E-Q.: Microphase separation facilitating and stabilizing hierarchical segment self-assembly of combined main-chain/side-chain liquid crystalline polymer in diblock copolymer. Macromolecules, 46, 5249-5259 (2013). DOI: $10.1021 / \mathrm{ma} 400325 \mathrm{~g}$

[46] Yu Z-Q., Lam J. W. Y., Zhao K., Zhu C-Z., Yang S., Lin J-S., Li B. S., Liu J-H., Chen E-Q., Tang B. Z.: Mesogen jacketed liquid crystalline polyacetylene containing triphenylene discogen: Synthesis and phase structure. Polymer Chemistry, 4, 996-1005 (2013). DOI: $10.1039 / \mathrm{c} 2$ py20535a

[47] Yin X-Y., Ye C., Ma X., Chen E-Q., Qi X-Y., Duan XF., Wan X-H., Cheng S. Z. D., Zhou Q-F.: Manipulating supramolecular self-assembly via tailoring pendant group size of linear vinyl polymers. Journal of the American Chemical Society, 125, 6854-6855 (2003). DOI: $10.1021 / \mathrm{ja034462z}$

[48] Xie H-L., Jie C-K., Yu Z-Q., Liu X-B., Zhang H-L., Shen Z., Chen E-Q., Zhou Q-F.: Hierarchical supramolecular ordering with biaxial orientation of a combined main-chain/side-chain liquid-crystalline polymer obtained from radical polymerization of 2-vinylterephthalate. Journal of the American Chemical Society, 132, 8071-8080 (2010).

DOI: $10.1021 / \mathrm{ja} 101184 \mathrm{u}$

[49] Weng L., Yan J-J., Xie H-L., Zhong G-Q., Zhu S-Q., Zhang H-L., Chen E-Q.: Design, synthesis, and selfassembly manipulating of polymerized ionic liquids contained imidazolium based on 'Jacketing' effect. Journal of Polymer Science Part A: Polymer Chemistry, 51, 1912-1923 (2013). DOI: $10.1002 /$ pola.26585 
[50] Kouwer P. H. J., Swager T. M.: Synthesis and mesomorphic properties of rigid-core ionic liquid crystals. Journal of the American Chemical Society, 129, 14042 14052 (2007). DOI: $10.1021 /$ ja075651a

[51] Tezuka Y., Goethals E. J.: Ion exchange and ring-opening reactions of telechelic poly(tetrahydrofuran)s containing terminal cyclic quaternary ammonium salts. Die Makromolekulare Chemie, 188, 783-789 (1987). DOI: $10.1002 / \mathrm{macp} .1987 .021880412$

[52] Cheng S., Zhang M., Wu T., Hemp S. T., Mather B. D., Moore R. B., Long T. E.: Ionic aggregation in random copolymers containing phosphonium ionic liquid monomers. Journal of Polymer Science Part A: Polymer Chemistry, 50, 166-173 (2012).

DOI: $10.1002 /$ pola. 25022

[53] Ye Y., Elabd Y. A.: Anion exchanged polymerized ionic liquids: High free volume single ion conductors. Polymer, 52, 1309-1317 (2011).

DOI: $10.1016 /$ j.polymer.2011.01.031

[54] Lee M., Choi U. H., Salas-de la Cruz D., Mittal A., Winey K. I., Colby R. H., Gibson H. W.: Imidazolium polyesters: Structure-property relationships in thermal behavior, ionic conductivity, and morphology. Advanced Functional Materials, 21, 708-717 (2011).

DOI: $10.1002 / \mathrm{adfm} .201001878$

[55] Rajendran S., Prabhu M. R., Rani M. U.: Ionic conduction in poly(vinyl chloride)/poly(ethyl methacrylate)based polymer blend electrolytes complexed with different lithium salts. Journal of Power Sources, 180, 880-883 (2008).

DOI: 10.1016/j.jpowsour.2008.02.063

[56] Yoshizawa M., Ohno H.: Synthesis of molten salt-type polymer brush and effect of brush structure on the ionic conductivity. Electrochimica Acta, 46, 1723-1728 (2001). DOI: $10.1016 / \mathrm{S} 0013-4686(00) 00777-5$

[57] Vygodskii Y. S., Mel'nik O. A., Shaplov A. S., Lozinskaya E. I., Malyshkina I. A., Gavrilova N. D.: Synthesis and ionic conductivity of polymer ionic liquids. Polymer Science Series A, 49, 256-261 (2007).

DOI: $10.1134 / \mathrm{S} 0965545 \mathrm{X} 07030042$

[58] Hunley M. T., England J. P., Long T. E.: Influence of counteranion on the thermal and solution behavior of poly(2-(dimethylamino)ethyl methacrylate)-based polyelectrolytes. Macromolecules, 43, 9998-10005 (2010). DOI: $10.1021 / \mathrm{ma1017499}$

[59] Pont A-L., Marcilla R., De Meatza I., Grande H., Mecerreyes D.: Pyrrolidinium-based polymeric ionic liquids as mechanically and electrochemically stable polymer electrolytes. Journal of Power Sources, 188, 558-563 (2009).

DOI: 10.1016/j.jpowsour.2008.11.115

[60] Pu K-Y., Fang Z., Liu B.: Effect of charge density on energy-transfer properties of cationic conjugated polymers. Advanced Functional Materials, 18, 1321-1328 (2008).

DOI: $10.1002 / \mathrm{adfm} .200701018$
[61] Spiliopoulos I. K., Mikroyannidis J. A.: Blue-lightemitting poly(phenylenevinylene)s with alkoxyphenyl substituents: Synthesis and optical properties. Macromolecules, 35, 2149-2156 (2002).

DOI: $10.1021 / \mathrm{ma} 011409 \mathrm{r}$

[62] Goudreault T., He Z., Guo Y., Ho C-L., Zhan H., Wang Q., Ho K. Y-F., Wong K-L., Fortin D., Yao B., Xie Z., Wang L., Kwok W-M., Harvey P. D., Wong W-Y.: Synthesis, light-emitting, and two-photon absorption properties of platinum-containing poly(arylene-ethynylene)s linked by 1,3,4-oxadiazole units. Macromolecules, 43, 7936-7949 (2010).

DOI: $10.1021 / \mathrm{ma} 1009319$

[63] Itami K., Yamazaki D., Yoshida J-I.: Pyrimidine-core extended $\pi$-systems: General synthesis and interesting fluorescent properties. Journal of the American Chemical Society, 126, 15396-15397 (2004).

DOI: $10.1021 / \mathrm{ja} 044923 \mathrm{w}$

[64] Barik S., Bletzacker T., Skene W. G.: $\pi$-conjugated fluorescent azomethine copolymers: Opto-electronic, halochromic, and doping properties. Macromolecules, 45, 1165-1173 (2012). DOI: $10.1021 / \mathrm{ma} 2024304$

[65] Bhowmik P. K., Han H., Cebe J. J., Nedeltchev I. K., Kang S-W., Kumar S.: Synthesis and characterization of poly(pyridinium salt)s with organic counterions exhibiting both thermotropic liquid-crystalline and light-emitting properties. Macromolecules, 37, 2688-2694 (2004). DOI: $10.1021 / \mathrm{ma} 030460 \mathrm{n}$

[66] Yang J., He G. S., Zhang B., Luo W. A., Chen X. D., Fu R. W., Zhang M. Q.: Interfacial adhesion of nanoparticles in polymer blends by intrinsic fluorescence spectra. Express Polymer Letters, 5, 799-808 (2011). DOI: $10.3144 /$ expresspolymlett.2011.78

[67] Geddes C. D., Lakowicz J. R.: Advanced concepts in fluorescence sensing: Part A: Small molecule sensing. Springer, New York (2007).

[68] Yang J., Liu M. K., Zhang B., Chen X. D., Fu R. W., Zhang M. Q.: Intrinsic fluorescence studies of compatibility in thermoplastic phenol formaldehyde resin/poly (ع-caprolactone) blends. Express Polymer Letters, 8, 698-707 (2011). DOI: $10.3144 /$ expresspolymlett.2011.68

[69] Zhelev Z., Ohba H., Bakalova R.: Single quantum dotmicelles coated with silica shell as potentially non-cytotoxic fluorescent cell tracers. Journal of the American Chemical Society, 128, 6324-6325 (2006). DOI: $10.1021 / \mathrm{ja061137d}$

[70] Zhang D., Liu Y., Wan X., Zhou Q-F.: Synthesis of a new side-chain type liquid crystal polymer poly[dicyclohexyl vinylterephthalate]. Macromolecules, 32, 4494-4496 (1999).

DOI: $10.1021 / \mathrm{ma} 9901386$ 